Sharif University of Technology
Scientia Iranica
Transactions E: Industrial Engineering
hCIENTIA

\title{
A sustainable closed-loop location-routing-inventory problem for perishable products
}

\author{
F. Navazi, Z. Sazvar*, and R. Tavakkoli-Moghaddam \\ School of Industrial Engineering, College of Engineering, University of Tehran, Tehran, Iran.
}

Received 21 March 2020; received in revised form 25 December 2020; accepted 25 January 2021

\author{
KEYWORDS \\ Closed-loop supply \\ chain; \\ Location-routing- \\ inventory problem; \\ Perishability; \\ Simultaneous pickup \\ and delivery; \\ Sustainability; \\ Multi-objective \\ meta-heuristics.
}

\begin{abstract}
Perishable products may expire if their holding time exceeds their shelf-life. In this study, along with designing a forward flow to distribute perishable products, the remaining perished products at retailers can be gathered for recycling during fresh product distribution. To mitigate waste, recycled products are offered to a secondary market. A mathematical model for this Closed-Loop Location-Routing-Inventory Problem (CLLRIP) is developed by considering multi-compartment trucks, simultaneous pickup and delivery, technology selection, and the risk of urban traffic. Based on three sustainability pillars, three objective functions are considered. This way, the interests of the network's three main stakeholders are embedded. The proposed model is solved by the TorabiHassini method. Two evolutionary algorithms, including Non-Dominated Sorting Genetic Algorithm-II (NSGA-II) and a new hybrid one, are also developed to solve large-sized cases of the NP-complete problem. Statistical tests show the superiority of the hybrid algorithm in the Computational Time (CT) metric, which is about 0.4 NSGA-II's CT. The results indicate the importance of closing the network loop for perishable products. Finally, the sensitivity analysis determined that $83.33 \%$ decrease in recycled product's sale price caused $9.08 \%$ increase in costs, $2.77 \%$ decrease in environmental side-effects, and $5.16 \%$ decrease in social objectives, which are significant.
\end{abstract}

(C) 2023 Sharif University of Technology. All rights reserved.

\section{Introduction}

The distribution type of product wastage involves a remarkable part of losses, especially for perishable products such as food and vegetables [1]. Meanwhile, in some societies, children suffer from malnutrition [2]. Even in some populated developing or developed

\footnotetext{
*. Corresponding author. Tel.: +9821 82084483;

Fax: +982188013102

E-mail addresses: f.navazi@ut.ac.ir (F. Navazi);

sazvar@ut.ac.ir(Z.Sazvar); tavakoli@ut.ac.ir (R.

Tavakkoli-Moghaddam)
}

doi: $10.24200 /$ sci. 2021.55642 .4353 countries, adults suffer from food poverty [3]. According to Parfitt et al. [3], in 2050, nine billion people are going to be fed by the same earth resources that exist now. Meanwhile, the agriculture fields lose their fertility for agro-food products after several harvests [4]. Perishable products begin to deteriorate when their shelf-life expires. Therefore, some parts of a retailer's perishable inventories can perish in each period because of quality loss, outdatedness, etc. [5].

Sustainable Supply Chain Management (SSCM) refers to designing products and distribution networks, causing no harm to recent or future generations considering the economic, environmental, and social consequences [6]. Thus, satisfaction of all stakeholders in the 
supply chain should be taken into account. According to Eskandarpour et al. [7], there are three main stakeholders in a supply chain, including customers, personnel who are working in the supply chain, and the local community affected by the supply chain activities.

A product can complete its life cycle by integrating forward and reverse logistics in the Closed-Loop Supply Chains (CLSCs). In addition to the forward flow of materials from suppliers to customers, the collection and management of perished products through reusing, recycling, etc. are addressed in CLSCs [8].

To reduce urban wastes, perishable products that have not perished yet but lost their quality can be offered to a secondary market after reprocessing [5]. Govindan et al. [2] stated that low-quality products could be sold at a secondary market at a lower price, especially in societies in which people in various areas have different Maximum Willingness to Pay (MWP). Thus, a CLSC can help reduce resource consumption and waste generation to achieve global sustainability [9].

This paper is among the first studies that deals with a Closed-Loop Location-Routing-Inventory Problem (CL-LRIP) considering (a) simultaneous pickup and delivery for perishable products, (b) the possibility of selling recycled products to a secondary market, (c) the possibility of applying different technologies, each one with specified economic, social, and environmental specifications at DCs and RCs, and (d) applying multicompartment trucks in a Vehicle Routing Problem (VRP) with simultaneous pickup and delivery to reduce transport costs besides energy and fuel consumption of the trucks. By this contribution, there is no need to use two different fleets for delivering fresh products and picking up the remaining products (visiting each retailer twice). Utilizing multi-compartment vehicles are inspired by Moon et al. [10] who utilized a multicompartment fleet for different types of products.

This problem is inspired by real-world observations. For instance, some of the applications of the proposed model are in fruit/vegetable distribution networks in which DCs dispatch products to retailers, but the remaining unsold products can be sold at a lower price to workshops, which produce dried fruits/vegetables to supply part of their demand. In the industrial bread case, one of the resources used to supply bread demands (versus bakeries), people usually avoid buying low-quality or stale bread, which can be collected and turned into toasted flour for humans or animals and poultry feed. There are similar examples in dairy industry, fashion industry, and cut flower supply chains, which unsoldflowers can be carried to some workshops to produce dry decorative flowers, scent, etc.

A mathematical model is developed to formulate the CL-LRIP of a network including a supplier, Distri- bution Centers (DCs), retailers/customers, Recycling Centers (RCs), and a Central Disposal Center (CDC). The proposed model aims to make decision about: the location of active DCs in the CL-LRIP, the product distribution routes from DCs to retailers, the optimal and eco-friendly inventory policy of retailers, the location of the RCs for collecting/recycling perished low-quality products to turn them into the second product. Also, it identifies the impacts of the leading stockholder's utility functions on optimal location, routing, and inventory decisions, the impacts of multicompartment trucks on CL-LRIP, and the impacts of recycled product sale on sustainability pillars.

In this paper, three objective functions are considered. The first objective function attempts to minimize costs. The second one concentrates on environmental side effects by proposing a new model to calculate them based on the weight of fresh and expired products carried simultaneously by multi-compartment trucks and the distance between nodes. In the third objective function, the impacts of opening DCs/RCs on increasing job opportunities and balanced economic development for local communities, which are two main aspects of Social Responsibility (SR) [11], are considered. The interests of two other groups of stakeholders, including customers and personnel, are maintained by their utility functions.

The remainder of the paper is organized as follows: Section 2 involves a review of related literature. Section 3 presents the mathematical formulation of the problem. Section 4 provides a real-case study, which is solved by an exact method, and two developed multi-objective meta-heuristic algorithms. Section 5 reports numerical results and sensitivity analysis in detail. The final section discusses conclusions and some future directions.

\section{Literature review}

Following a review of related studies, we found that SSCM was first defined by Seuring and Müller [6] as a balance among economic, environmental, and social aspects. Numerous studies on SSCM have merely focused on economic and environmental issues, perhaps due to international goals set by the European Commission, e.g., reduction of 500 million tons of GHG emissions from the year 2015 to 2035 [12]. However, social aspects of sustainability are a matter of great concern, especially in labor-intensive industries. In Table 1, some social criteria studied in quantitative models are summarized.

Integration of forward and reverse logistics that causes the formation of a CLSC [13] strongly influences three pillars of sustainability. For instance, by using the same facilities/resource/workforce for the distribution and collection and the same fleet for the line-haul and 
Table 1. Social criteria considered in some recent SSCM studies.

\begin{tabular}{|c|c|c|c|c|}
\hline Article & Problem type & Economic & Environmental & Social \\
\hline Devika et al. [5] & CLSC network design & Total cost & Environmental impact & $\begin{array}{l}\text { Fixed \& variable } \\
\text { job creation Personnel } \\
\text { damage at the time } \\
\text { of facility establishment }\end{array}$ \\
\hline Rahimi et al. [16] & IRP & Total profit & Noise Emission & $\begin{array}{l}\text { Vehicle accidents Number } \\
\text { of expired products }\end{array}$ \\
\hline $\begin{array}{l}\text { Khalili-Damghani } \\
\text { et al. [17] }\end{array}$ & LRP & Total cost & - & $\begin{array}{l}\text { Balance of workload } \\
\text { of DCs personnel }\end{array}$ \\
\hline Zhalechian et al. [11] & LRIP in CLSC & Total cost & $\begin{array}{l}\text { Energy consumption } \\
\mathrm{CO}_{2} \text { emission }\end{array}$ & $\begin{array}{l}\text { Job creation } \\
\text { Economic development }\end{array}$ \\
\hline Rabbani et al. [18] & Transportation LRP & Total cost & $\begin{array}{l}\text { Fuel consumption } \\
\mathrm{CO}_{2} \text { emission }\end{array}$ & $\begin{array}{l}\text { Personnel interests (balancing } \\
\text { drivers route length) } \\
\text { Customers satisfaction } \\
\text { (soft time windows) }\end{array}$ \\
\hline Sazvar et al. [19] & Transportation Inventory & Total cost & $\mathrm{CO}_{2}$ emission & Public health \\
\hline $\begin{array}{l}\text { Sazvar and } \\
\text { Sepehri [20] }\end{array}$ & Inventory & Total profit & GHG emission & $\begin{array}{l}\text { Job creation for native } \\
\text { labor instead of } \\
\text { unemployed immigrant labor }\end{array}$ \\
\hline
\end{tabular}

back-haul, the amounts of wastes/environmental sideeffects as well as costs are reduced [14]. In designing forward and reverse logistics, only strategic decision levels (e.g., Facility Location Problem (FLP)) are taking into account (i.e., facilities are connected only by the flow balancing equations, which are an elementary type of connection) [15]. However, these connections play an important role in energy consumption rates and operational network costs. Therefore, in this study, VRP decisions are integrated. A comprehensive literature review of CLSC was presented by Govindan et al. [8].

Based on sustainable development pillars, since the inventory management of the deteriorating products, divided into perishable and decaying products by Bakker et al. [21], can give rise to environmental protection, job creation, and financial benefits [22], this study focuses on perishable products. Challenges intensify in the case of managing the transportation and vehicle routing of perishable products, given their impact on the environment [23]. A systematic review was conducted on inventory models of perishable prod- ucts by Chaudhary et al. [24]. Different approaches to modeling perishability of products were found: expiration after passing product shelf life $[25,26]$, expiration of a specific percentage of inventory per period $[27,20]$, a nonlinear holding cost function depending on the product life cycle/amount of remaining inventories $[28,29]$, and combination of the three previously mentioned techniques [30].

Recently, the concept of sustainability is raised in the IRP. Rahimi et al. [16] considered lower selling price for products with a longer age and found that exceeding the shelf life of a product would lead to spoilage. They added the concept of reverse logistics to the IRP to increase the distribution network sustainability for perishable products. Moreover, Rahimi et al. [31] formulated a fuzzy multi-objective IRP model that considers maximizing profit, maximizing service level, and minimizing the GHG emissions of network activities

In this paper, the Location-Routing-Inventory Problem (LRIP) that was introduced by Ahmadi Javid and Azad [32] by integrating the LRP, which is re- 
viewed by Prodhon and Prins [33] with IRP is included in a CLSC. In the LRIP, different decision-making levels including strategic (i.e., location), tactical (i.e., routing), and operational (i.e., inventory) ones are integrated.

A two-stage multi-product LRIP with stochastic demand and travel time was studied by Nekooghadirli et al. [34]. In their two-objective problem, which minimizes the total cost and maximum meantime of delivering commodities to customers, $(R, Q)$ ordering policy with a Safety Stock (SS) is used. A multiproduct LRIP with the back-ordered demand and split-sourcing was solved by Ghorbani and Akbari Jokar [35] with the application of the automobile industry. The order and shortage amount and inventory level at the end of the period were added as decision variables. They developed an efficient hybrid imperialist competitive-simulated annealing algorithm to find near-optimal solutions. Tavakkoli-Moghaddam and Raziei [36] considered a bi-objective multi-product LRIP with a heterogeneous fleet and a fuzzy demand, which minimized the cost of the two-echelon network and the total lost sales. They used the Torabi-Hassini's (TH) method to solve the problem by GAMS software. A generalized Benders decomposition method was developed by Zheng et al. to solve an integrated locationinventory-routing problem for the supply chain design [37]. Because of the LRIP complexity, Karakostas et al. [38] solved an LRIP with distribution outsourcing via a variable neighborhood search-based meta-heuristic algorithm.

With the advent of the SSCM, sustainable LRIP has also received the attention of some researchers. Zhalechian et al. [11] formulated the LRIP in a CLSC for the automobile industry by considering three pillars of sustainability (i.e., the economic, environmental, and social impacts). They integrated reverse and forward logistics by using common facilities for collecting and distributing. However, in the current study, the same fleet for forward and backward flows is utilized. In Table 2, a summary of the existing articles that address sustainability along with location, routing, and inventory problems is given.

According to Table 2, a limited number of re-

Table 2. Significant features of the current study versus other related articles.

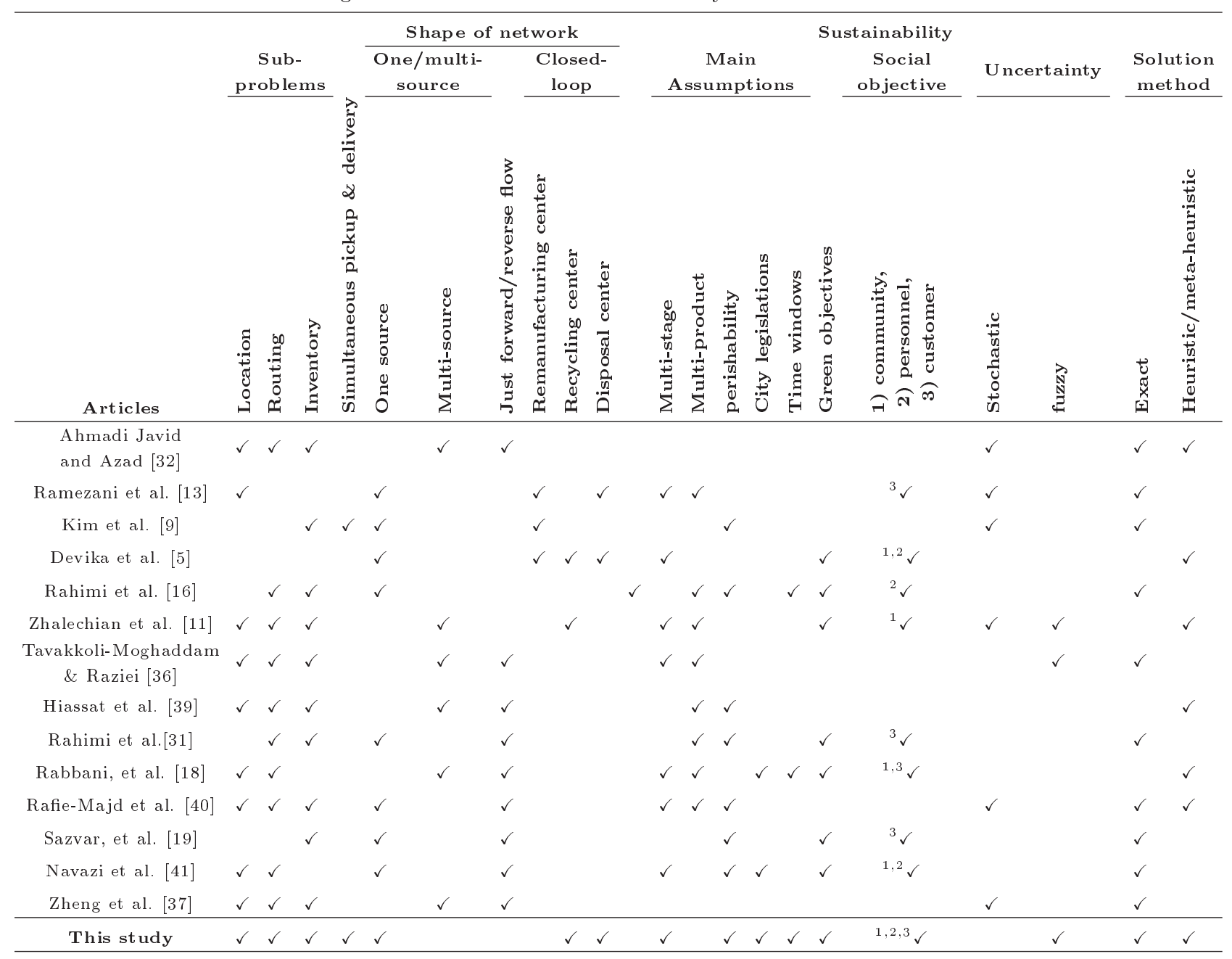


searches on the LRIP concentrate on perishable products. For instance, by considering a limited deterministic shelf life for products, Hiassat et al. [39] developed a Mixed-Integer Linear Programming (MILP) model to solve the LRIP for a perishable product. Their results confirm the benefits of integrating different decision levels. Rafie-Majd et al. [40] developed a Lagrangian relaxation algorithm to solve the LRIP for multi-perishable products that should be delivered in a limited time horizon. However, some real assumptions have not been studied in previous models such as gathering perished products via VRP with simultaneous pickup and delivery; using multi-compartment trucks for forward and backward flows; collecting expired products, turning them into the second-hand product in RCs, and selling them in a secondary market; considering all sustainable development pillars; and preserving the interest of three main supply chain stakeholders.

This paper tries to cover the aforementioned gaps. The main contributions of this study are as follows:

- Considering reverse logistics in a CL-LIRP by locating some RCs and, then, selling their recycled products to a secondary market;

- Concentrating on perishable products, technology selection, GHG emission, and the risk of urban traffic along with sustainability requirements in LRIP;

- Considering multi-compartment trucks for simultaneous pickup and delivery in a CL-LRIP. This way, a new formulation is developed to calculate the Fuel/energy Consumption Rate (FCR) and GHG emission of the multi-compartment trucks and other fleets based on their load weight;

- Focusing on the social satisfaction of the three main stakeholders of the supply chain by developing a new quantitative formulation to calculate satisfaction as the social objective function. However, in most studies, just one group of stakeholders is considered;

- Developing two evolutionary algorithms, including a new hybrid, with a new customized solution representation to solve the developed multi-objective large-sized problems.

\section{Problem description and mathematical formulation}

This study aims to achieve an efficient plan for a sustainable closed-loop network for perishable products by integrating forward and reverse flows. Three echelons of the forward flow are plant, DCs, and retailers. Traffic restrictions of the populated cities on the entry of lorries prohibit a direct connection between the supplier and retailers and add an echelon between a supplier and retailers. In this one source problem, a supplier (e.g., far distant factory, orchard, garden, far-field, and the like) must supply the uncertain demands of retailers through several DCs. Products should first be received by DCs and then, delivered to retailers. Retailers are prioritized based on their loyalty. The location of active DCs, as intermediate facilities with limited capacities, should be selected from some potential points in the city's outskirts (DCs location decision). In addition, the technology level of active DCs should be specified among solar, gasoline, and oil (DCs technology level decision). The number of lorries should also be determined (forward flow transportation decision).

Product delivery should take place in the soft time windows of the DCs. Otherwise, it would incur a penalty cost. A soft time window is also included for retailers/customers. Unlike DCs, the violation of the retailer's time windows affects the satisfaction level of customers in the social criterion. The time of fast unloading and loading products in DCs is ignorable in comparison to other times of distribution activities. Therefore, DCs do not hold inventories.

DCs should deliver products to retailers by some smaller trucks as soon as possible. Since smaller trucks are multi-compartment, the forward and reverse flows are joined together. We attempted to improve network performance by sharing the transportation fleet in the forward and reverse flows. Each compartment of the truck has a limited capacity. The cold compartment for transporting fresh products consumes energy to provide an appropriate cold temperature. Retailers keep inventory until the next visit (order quantities and inventories decisions). The no freezer compartment of the truck is for picking up the retailer's perished products and handing them over to the RCs. The model should also find an optimal location for operated RCs among some potential points (RCs location decision). After connecting the last retailer of the route to an $\mathrm{RC}$, the mission of the multi-compartment truck finishes (multi-compartment VRP with simultaneous pickup and delivery decisions). The risk of urban traffic is also considered, which influences traveling time and time of delivery. There is no necessity for multi-compartment trucks to come back to their departure DCs in each period. Therefore, open VRP is encountered. Keeping the routes open instead of closing them to departure DCs can help drivers reach their home sooner and increase their work satisfaction.

Usable perished products are reprocessed and turned into new products for the secondary market in operated RCs. Value-added products can be sold to a secondary market with a notable price to compensate for the collecting and recycling expenditures. Sending unusable perished products from RCs to bury in the CDC by homogeneous fleet forms a transportation 


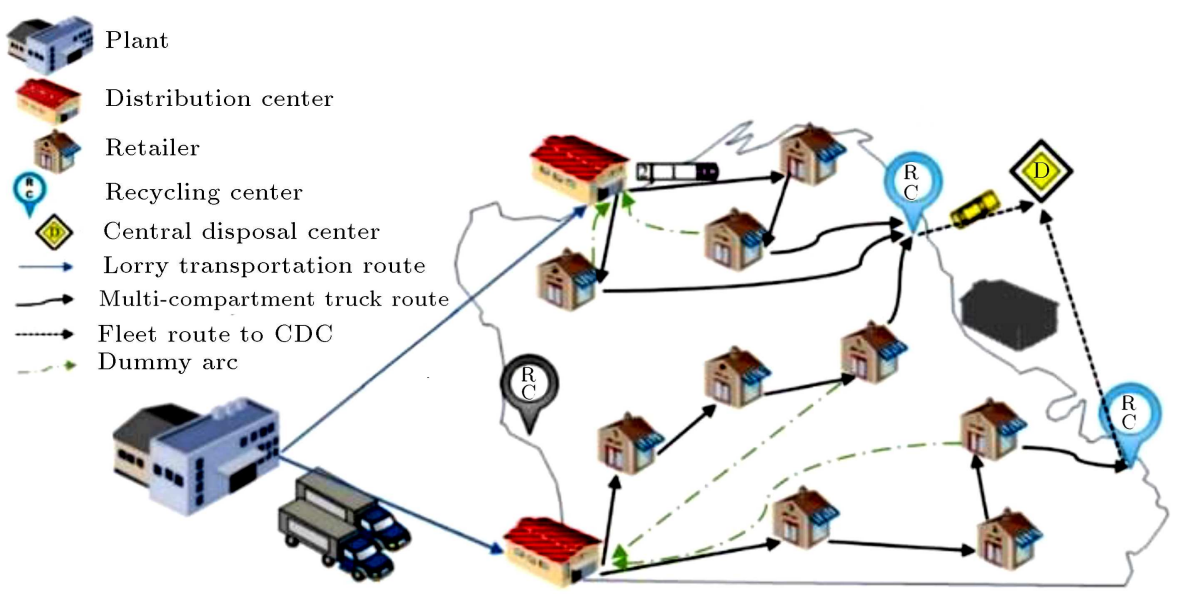

Figure 1. Schematic of the CL-LRIP.

phase at the end (reverse flow transportation decision). A schematic view of the considered CL-LRIP is shown in Figure 1.

The problem has three objective functions according to the three pillars of sustainability. The traditional goal of the problem is to minimize network costs. The second objective function, called the green objective function, tries to minimize energy consumption and destructive environmental effects of activating DCs and operating RCs based on their technology levels; it also minimizes fuel consumption and $\mathrm{CO}_{2}$ emission of lorries, multi-compartment trucks, and homogeneous fleets based on their traveled distance and the weight of their load. This way, the fuel consumption formulation for classic VRP presented by Soysal [42] is extended to VRP with simultaneous pickup and delivery. The energy consumption of cooling equipment of multicompartment trucks is calculated by a similar formulation based on a load of fresh products.

The third objective function, called the social objective function, aims to maximize the satisfaction of three main stockholders. This way, the retailers' satisfaction is defined based on a utility function upon considering time windows for retailers. Simultaneously, the DCs' personnel satisfaction is maximized by activating the DCs, which have a reasonable distance from personnel location. For maximizing the local community's satisfaction, improving the economic development of regions besides job creation is considered by allocating the required number of personnel to DCs/RCs.

\section{Assumptions}

- The plant has enough capacity to satisfy all retailers' demands;

- The location of the plant, retailers, and CDC is predefined and fixed;
- The plant and DCs do not keep the inventory. The products are fresh while leaving the plant;

- The demands of retailers are uncertain and independent;

- A dummy arc with zero cost and time is considered between the last retailer and the origin DC of a route to model simplicity.

\section{Notations}

Indices and sets:

$\begin{array}{ll}O \in\{1\} & \text { Plant } \\ t \in\{1,2, \ldots, T\} & \text { Time periods } \\ d \in\{1,2, \ldots, D\} & \text { Potential DCs } \\ g \in\{1,2, \ldots, G\} & \text { Technology levels of DCs (e.g., } \\ & \text { gas, solar, and electricity) } \\ i \in\{1,2, \ldots, I\} & \text { Retailers } \\ r \in\{1,2, \ldots, R\} & \text { Potential RCs } \\ s \in\{1,2, \ldots, S\} & \text { Technology levels of RCs } \\ c d c \in\{1\} & \text { Central disposal center } \\ l \in\{1,2, \ldots, L\} & \text { Network personnel location } \\ m \in\{1,2, \ldots, D+I\} & \text { Potential DCs and retailers nodes } \\ m^{\prime} \in\{1,2, \ldots, D+I+R\} & \text { Potential DCs, retailers, } \\ & \text { and potential RCs nodes }\end{array}$

Parameters:

$\tilde{d}_{i t} \quad$ Fuzzy demand of retailer $i$ in period $t$

Ql Capacity of a lorry

$D p d_{d} \quad$ Distance of the plant to DC $d$

$t t_{d} \quad$ Travel time from the plant to DC $d$

$\mathrm{Ce} \quad \mathrm{CO}_{2}$ emission from one-liter fuel consumption

$C l_{d t} \quad$ Transportation cost per $\mathrm{km}$ for a lorry from plant to $\mathrm{DC} d$ in period $t$

$F C R l^{0} \quad$ Fuel consumption rate of an empty

$\left(F C R l^{1}\right) \quad$ (fully-loaded) lorry per kilometer 


\begin{tabular}{|c|c|c|c|}
\hline$w l^{0}$ & Weight of an empty lorry & $p r_{i}$ & Priority coefficient of retailer $i$ \\
\hline$w l^{1}$ & $\begin{array}{l}\text { Weight of a fully-loaded lorry } \\
\left(w l^{1}=w l^{0}+Q l\right)\end{array}$ & $\left(t \tilde{w}_{i t}\right)$ & $\begin{array}{l}\text { Desired time window of retailer } i \text { in } \\
\text { period } t \text { by a trapezoidal fuzzy number, }\end{array}$ \\
\hline \multirow[t]{2}{*}{$f d_{d g t}$} & Fixed activation cost of DC $d$ with & & $t \tilde{w}_{i t}=\left(t w_{1 i t}, t w_{2 i t}, t w_{3 i t}, t w_{4 i t}\right)$ \\
\hline & technology level $g$ in period $t$ & $h_{i t}$ & Inventory holding cost of retailer $i$ in \\
\hline \multirow[t]{2}{*}{$c e_{d g}$} & Carbon emission of DC $d$ with & & period $t$ \\
\hline & technology $g$ & $\operatorname{cap}_{i}$ & Depot capacity of retailer $i$ \\
\hline \multirow{3}{*}{$\begin{array}{l}Q_{d} \\
{\left[e_{d t}, l_{d t}\right]}\end{array}$} & Maximum capacity of DC $d$ & $\theta$ & Percentage of perished products that \\
\hline & The soft time window of $\mathrm{DC} d$ in & & should be disposed \\
\hline & period $t$ & $f r_{r s t}$ & Fixed operating cost of RC $r$ with \\
\hline \multirow[t]{2}{*}{$P e_{t}\left(P l_{t}\right)$} & Penalty cost for violating the earliest & \multirow[b]{2}{*}{$c e_{r s}$} & technology level $s$ in period $t$ \\
\hline & $\begin{array}{l}\text { (latest) time of DC's time windows in } \\
\text { period } t\end{array}$ & & $\begin{array}{l}\text { Carbon emission of RC } r \text { with } \\
\text { technology } s\end{array}$ \\
\hline \multirow[t]{2}{*}{$r p_{d g}$} & Required number of personnel for DC & $Q_{r}$ & Maximum capacity of RC $r$ \\
\hline & $d$ with technology $g$ & $P_{t}$ & Selling price of recycled products in \\
\hline \multirow[t]{2}{*}{$r p_{r s}$} & Required number of personnel for $\mathrm{RC}$ & \multirow[b]{2}{*}{$b d_{r}$} & the secondary market in period $t$ \\
\hline & $r$ with technology $s$ & & Distance of $\mathrm{RC} r$ to the $\mathrm{CDC}$ \\
\hline \multirow[t]{2}{*}{$d p_{l d}$} & Distance of the personnel in location & $Q f$ & Capacity of a homogeneous fleet \\
\hline & $l$ from $\mathrm{DC} d$ & $C f_{r t}$ & Transportation cost of a fleet from \\
\hline \multirow[t]{2}{*}{$\tilde{a}_{l}$} & Desired distance from a DC for & \multirow[b]{2}{*}{$\begin{array}{l}F C R f^{0} \\
\left(F C R f^{1}\right)\end{array}$} & $\mathrm{RC} r$ to the $\mathrm{CDC}$ in period $t$ \\
\hline & $\begin{array}{l}\text { personnel in location } l \text { stated } \\
\text { by a trapezoidal fuzzy number, } \\
\tilde{a_{l}}=\left(a_{1 l}, a_{2 l}, a_{3 l}, a_{4 l}\right)\end{array}$ & & $\begin{array}{l}\text { Fuel consumption rate of an empty } \\
\text { (fully-loaded) fleet per kilometer }\end{array}$ \\
\hline \multirow{3}{*}{$\begin{array}{l}b_{m^{\prime} n^{\prime}} \\
t t_{m n}\end{array}$} & Distance of node $m^{\prime}$ from node $n^{\prime}$ & \multirow[t]{2}{*}{$w f^{0}$} & Weight of an empty homogeneous \\
\hline & Time of traveling from node $m$ to & & fleet \\
\hline & node $n$ & $w f^{1}$ & $\begin{array}{l}\text { Weight of a fully-loaded homogeneous } \\
\text { fleet }\left(w f^{1}=w f^{0}+Q f\right)\end{array}$ \\
\hline$\varphi_{m n t}$ & $\begin{array}{l}\text { Urban traffic risk between nodes } m \\
\text { and } n \text { in period } t\end{array}$ & \multirow[t]{2}{*}{$r d_{d}\left(r d_{r}\right)$} & Regional development percentage for \\
\hline \multirow[t]{2}{*}{$F v$} & Fixed cost of hiring a multi- & & region $d$ (region $r$ ) \\
\hline & compartment $\mathrm{t}$ & \multirow{2}{*}{$i f_{d g}$} & Regional development impact of \\
\hline \multirow[t]{2}{*}{$Q_{1} t$} & Capacity of the first part of the & & activated $\mathrm{DC} d$ with technology $g$ \\
\hline & ti-compartment truck (freezer) & $i f_{r s}$ & Regional development impact of \\
\hline$E C R t^{1}$ & Energy consumption rate of the & $M$ & lology $s$ \\
\hline & cooling system of a fully-loaded & $M$ & A large arbitrary number \\
\hline & truck & Variables: & \\
\hline$Q_{2} t$ & $\begin{array}{l}\text { Capacity of the second part of the } \\
\text { multi-compartment truck (without }\end{array}$ & $N l_{d t}$ & $\begin{array}{l}\text { Number of lorries sent from the plant } \\
\text { to DC } d \text { in period } t\end{array}$ \\
\hline & freezer) & $N f_{r t}$ & Number of homogeneous fleets from \\
\hline$C t_{m^{\prime} n^{\prime} t}$ & Transportation cost per kilometer for & & $\mathrm{RC} r$ to the $\mathrm{CDC}$ in period $t$ \\
\hline & $\begin{array}{l}\text { a multi-compartment truck traveled } \\
\text { from node } m^{\prime} \text { to node } n^{\prime} \text { in period } t\end{array}$ & $V e_{d t}$ & $\begin{array}{l}\text { Violation amount from } e_{d t} \text {, the earliest } \\
\text { time of the soft time window of } \mathrm{DC} d\end{array}$ \\
\hline$F C R t^{0}$ & Fuel consumption rate of an empty & & \\
\hline$\left(F C R t^{1}\right)$ & $\begin{array}{l}\text { (fully-loaded) multi-compartment } \\
\text { truck per kilometer }\end{array}$ & $V l_{d t}$ & $\begin{array}{l}\text { Violation amount from } l_{d t} \text {, the latest } \\
\text { time of the soft time window of } \mathrm{DC} d\end{array}$ \\
\hline$w t^{0}$ & Weight of an empty multi- & & in period $t$ \\
\hline & compartment truck & $V_{d t}$ & $\begin{array}{l}\text { Number of products sent from plant to } \\
\text { DC } d \text { in period } t\end{array}$ \\
\hline$w t^{1}$ & $\begin{array}{l}\text { Weight of a fully-loaded multi- } \\
\text { compartment truck }\left(w t^{1}=w t^{0}+\right.\end{array}$ & $a t_{i t}$ & Arrival time at retailer $i$ in period $t$ \\
\hline & $\left.Q_{1 t}+Q_{2 t}\right)$ & $w_{l d t}$ & $\begin{array}{l}1 \text { if personnel } l \text { allocated to DC } d \text { in } \\
\text { period } t ; 0 \text {, otherwise }\end{array}$ \\
\hline
\end{tabular}


$y_{d t}^{g} \quad 1$ if DC $d$ with technology $g$ is activated in period $t$; 0 , otherwise

$y_{r t}^{s} \quad 1$ if RC $r$ with technology $s$ is operated in period $t ; 0$, otherwise

$z_{i d t} \quad 1$ if retailer $i$ is allocated to $\mathrm{DC} d$ in period $t ; 0$, otherwise

$y x_{i r}^{t} \quad 1$ if the last retailer $i$ connects to $\mathrm{RC} r$ in period $t$; 0 , otherwise

$x_{m n}^{t} \quad 1$ if node $m$ connects to node $n$ in period $t, m, n \in\{1,2, \ldots, D+I\} ; 0$, otherwise

$y n_{d t} \quad$ Auxiliary variable, 1 if $N l_{d t}>0 ; 0$, otherwise (i.e., $N l_{d t}=0$ )

$y f_{r t} \quad$ Auxiliary variable, 1 if $N f_{r t}>0 ; 0$, otherwise (i.e., $N f_{r t}=0$ )

$u_{m}^{t} \quad$ Deliverable load of a multicompartment truck before starting to serve node $m$ in period $t$

$u u_{m}^{t} \quad$ Picked load of a multi-compartment truck after serving node $m$ in period $t$

$I_{i t} \quad$ Inventory level of retailer $i$ at the end of period $t$

$q q_{i t} \quad$ Total quantity of received products by retailer $i$ in period $t$

$q_{i t t^{\prime}} \quad$ Quantity of received products by retailer $i$ in period $t$ for being used in period $t^{\prime}$

$e x_{i t} \quad$ Quantity of expired products in retailer $i$ at the end of period $t$

Based on the membership function of the trapezoidal fuzzy number $\tilde{a}_{l}$, the utility function of personnel $l$ working in $\mathrm{DC} d, u p_{l d}$, is defined as follows:

$$
u p_{l d}= \begin{cases}0 & d p_{l d}<a_{1 l} \text { or } d p_{l d}>a_{4 l} \\ \frac{d p_{l d}-a_{1 l}}{a_{2 l}-a_{1 l}} & a_{1 l} \leq d p_{l d}<a_{2 l} \\ 1 & a_{2 l} \leq d p_{l d} \leq a_{3 l} \\ \frac{a_{4 l}-d p_{l d}}{a_{4 l}-a_{3 l}} & a_{3 l}<d p_{l d} \leq a_{4 l}\end{cases}
$$

Similarly, the utility function of retailer $i$ in period $t, u c_{i t}$, is defined as Eq. (2) based on the desired arrival time $\left(t \tilde{w}_{i t}\right)$ stated by experts subjectively:

$$
u c_{i t}= \begin{cases}0 & a t_{i t}<t w 1_{i t} \quad \text { or } \quad a t_{i t}>t w 4_{i t} \\ \frac{a t_{i t}-t w 1_{i t}}{t w 2_{i t}-t w 1_{i t}} & t w 1_{i t} \leq a t_{i t}<t w 2_{i t} \\ 1 & t w 2_{i t} \leq a t_{i t} \leq t w 3_{i t} \\ \frac{t w 4_{i t}-a t_{i t}}{t w 4_{i t}-t w 3_{i t}} & t w 3_{i t}<a t_{i t} \leq t w 4_{i t}\end{cases}
$$

\subsection{Mathematical formulation}

Objective functions:

$$
\operatorname{Min} f_{1}=\sum_{t=1}^{T} \sum_{d=1}^{D} N l_{d t} C l_{d t} D p d_{d}
$$

$$
\begin{aligned}
& +\sum_{t=1}^{T} \sum_{d=1}^{D} \sum_{g=1}^{G} f d_{d g t} y_{d t}^{g} \\
& +\sum_{t=1}^{T} \sum_{d=1}^{D}\left(p e_{t} v e_{d t}+p l_{t} v l_{d t}\right) \\
& \sum_{t=1}^{T} \sum_{d=1}^{D} \sum_{i=1}^{I} f v x_{d i}^{t} \\
& +\sum_{t=1}^{T} \sum_{m=1}^{M} \sum_{n=1}^{M} C t_{m n t} b_{m n} x_{m n}^{t} \\
& +\sum_{t=1}^{T} \sum_{i=1}^{I} \sum_{r=1}^{R} C t_{i r t} b_{i r} y x_{i r}^{t} \\
& +\sum_{t=1}^{T} \sum_{r=1}^{R} \sum_{s=1}^{S} f r_{r s t} y_{r t}^{s} \\
& +\sum_{t=1}^{T} \sum_{r=1}^{R} N f_{r t} C f_{r t} b d_{r} \\
& +\sum_{t=1}^{T} \sum_{i=1}^{I} \frac{1}{2} h_{i t} I_{i t}-\sum_{t=1}^{T} \sum_{d=1}^{D} P_{t}(1-\theta) u u_{d}^{t} \\
& \operatorname{Min} f_{2}=\sum_{t=1}^{T} \sum_{d=1}^{D} \sum_{g=1}^{G} c e_{d g} y_{d t}^{g}+\sum_{t=1}^{T} \sum_{r=1}^{R} \sum_{s=1}^{S} c e_{r s} y_{r t}^{s} \\
& +\sum_{t=1}^{T} \sum_{d=1}^{D}(1+c e) D p d_{d} F C R l^{1}\left(N l_{t}-1\right) y n_{d t} \\
& +\sum_{t=1}^{T} \sum_{d=1}^{D}\left((1+c e) D p d_{d} F C R l^{0} y n_{d t}\right. \\
& +\left(\frac{F C R l^{1}-F C R l^{0}}{Q l}\right)\left(V_{d t}\right. \\
& \left.\left.-Q l\left(N l_{d t}-1\right) y n_{d t}\right)\right) \\
& +\sum_{t=1}^{T} \sum_{d=1}^{D} \sum_{i=1}^{I}(1+c e) b_{m i} x_{m i}^{t}\left(F C R t^{0}\right. \\
& \left.+\left(\frac{F C R t^{1}-F C R t^{0}}{Q 1 t+Q 2 t}\right)\left(u_{i}^{t}+u u_{m /\{D\}}^{t}\right)\right) \\
& +\sum_{t=1}^{T} \sum_{i=1}^{I} \sum_{r=1}^{R}(1+c e) b_{i r} y x_{i r}^{t}\left(F C R t^{0}\right. \\
& \left.+\left(\frac{F C R t^{1}-F C R t^{0}}{Q 1 t+Q 2 t}\right)\left(u_{i}^{t}+u u_{i}^{t}\right)\right)
\end{aligned}
$$




$$
\begin{aligned}
& +\sum_{t=1}^{T} \sum_{r=1}^{R}(1+c e) b d_{r} F C R f_{h f}^{1}\left(N f_{r t}-1\right) y f_{r t} \\
& +\sum_{t=1}^{T} \sum_{r=1}^{R}\left(( 1 + c e ) b d _ { r } \left(F C R f_{h f}^{0} y f_{r t}\right.\right. \\
& +\left(\frac{F C R f_{h f}^{1}-F C R t_{h f}^{0}}{Q f}\right)\left(\theta \sum_{i=1}^{I} u u_{i}^{t} y x_{i r}^{t}\right. \\
& \left.-Q f\left(N f_{r t}-1\right) y f_{r t}\right) \\
& +\sum_{t=1}^{T} \sum_{m=1}^{M} \sum_{i=1}^{I} b_{m i} x_{m i}^{t}\left(\frac{E C R^{1}}{Q 1 t}\right) u_{i}^{t} \\
\operatorname{Max}_{3} & =\alpha_{1} \sum_{t=1}^{T} \sum_{i=1}^{I} p r_{i} u c_{i t}+\alpha_{2} \sum_{t=1}^{T} \sum_{d=1}^{D} \sum_{l=1}^{L} w_{l d t} u p_{l d} \\
& +\alpha_{3}\left(\left\{\sum_{t=1}^{T} \sum_{d=1}^{D} \sum_{g=1}^{G} y_{d t}^{g} i f_{d g}\left(1-r d_{d}\right)\right.\right. \\
& \left.+\sum_{t=1}^{T} \sum_{r=1}^{R} \sum_{s=1}^{S} y_{r t}^{s} i f_{r s}\left(1-r d_{r}\right)\right\} \\
& \left.+\left\{\sum_{t=1}^{T} \sum_{d=1}^{D} \sum_{g=1}^{G} \sum_{s=1}^{S} y_{d t}^{g} r p_{d g} r p_{r s}\right\}\right) . \\
&
\end{aligned}
$$

\section{Constraints:}

$N l_{d t} \geq V_{d t} / Q l \quad \forall t \in T, \forall d \in D$,

$N l_{d t} \leq V_{d t} / Q l+1 \quad \forall t \in T, \forall d \in D$,

$V_{d t} \leq Q_{d} \sum_{g=1}^{G} y_{d t}^{g} \quad \forall t \in T, \forall d \in D$,

$\sum_{g=1}^{G} y_{d t}^{g} \leq 1 \quad \forall t \in T, \forall d \in D$

$V_{d t}=\sum_{i=1}^{I} y_{d t}^{g} q q_{i t} z_{i d t} \quad \forall t \in T, \forall d \in D$

$\sum_{d=1}^{D} z_{i d t}=1 \quad \forall t \in T, \forall i \in I$

$\sum_{i=1}^{I} z_{i d t} \leq M \sum_{g=1}^{G} y_{d t}^{g} \quad \forall t \in T, \forall d \in D$,
$\sum_{g=1}^{G} y_{d t}^{g} \leq \sum_{i=1}^{I} z_{i d t} \quad \forall t \in T, \forall d \in D$

$V e_{d t} \geq\left(e_{d t}-t t_{d}\right) \sum_{g=1}^{G} y_{d t}^{g} \quad \forall t \in T, \forall d \in D$,

$V l_{d t} \geq\left(t t_{d}-l_{d t}\right) \sum_{g=1}^{G} y_{d t}^{g} \quad \forall t \in T, \forall d \in D$,

$w_{l d t} \leq \sum_{g=1}^{G} y_{d t}^{g} \quad \forall t \in T, \forall d \in D, \forall l \in L$,

$\sum_{l=1}^{L} w_{l d t}=\sum_{g=1}^{G} r p_{d g} y_{d t}^{g} \quad \forall t \in T, \forall d \in D$

$\sum_{m=1}^{M} x_{i m}^{t}=1 \quad \forall t \in T, \forall i \in I, i \neq m$,

$\sum_{n=1}^{M} x_{n m}^{t}=\sum_{n=1}^{M} x_{m n}^{t} \quad \forall t \in T, \forall m \in M$,

$\sum_{d=1}^{D} x_{i d}^{t} u u_{i}^{t} \leq M \sum_{r=1}^{R} y x_{i r}^{t} \quad \forall t \in T, \forall i \in I$,

$\sum_{r=1}^{R} y x_{i r}^{t} \leq M \sum_{d=1}^{D} x_{i d}^{t} \cdot u u_{i}^{t} \quad \forall t \in T, \forall i \in I$,

$\sum_{r=1}^{R} y x_{i r}^{t} \leq 1 \quad \forall t \in T, \forall i \in I$,

$\sum_{i=1}^{I} y x_{i r}^{t} \leq M \sum_{s=1}^{S} y_{r t}^{s} \quad \forall t \in T, \forall r \in R$,

$\sum_{s=1}^{S} y_{r t}^{s} \leq \sum_{i=1}^{I} y x_{i r}^{t} \quad \forall t \in T, \forall r \in R$,

$\sum_{s=1}^{S} y_{r t}^{s} \leq 1 \quad \forall t \in T, \forall r \in R$,

$x_{i d}^{t} \leq z_{i d t} \quad \forall t \in T, \forall i \in I, \forall d \in D$,

$x_{d i}^{t} \leq z_{i d t} \quad \forall t \in T, \forall i \in I, \forall d \in D$,

$x_{i j}^{t}+z_{i d t}+\sum_{\substack{d=1 \\ d \neq d^{\prime}}}^{D} z_{j d^{\prime} t} \leq 2$

$\forall t \in T, \forall i, j \in I, i \neq j, \forall d \in D$, 


$$
\begin{aligned}
& \sum_{i=1}^{I} u u_{i}^{t} y x_{i r}^{t} \leq Q_{r} \sum_{s=1}^{S} y_{r t}^{s} \quad \forall t \in T, \forall r \in R \\
& u_{j}^{t}-u_{i}^{t}+x_{i j}^{t} Q 1 t+\left(Q 1 t-q q_{i t}-q q_{j t}\right) x_{j i}^{t} \leq Q 1 t-q q_{i t} \\
& \forall t \in T, \forall i, j \in I, i \neq j \\
& u u_{i}^{t}-u u_{j}^{t}+x_{i j}^{t} Q 2 t+\left(Q 2 t-e x_{i t}-e x_{j t}\right) x_{j i}^{t} \\
& \leq Q 2 t-e x_{j t}, \quad \forall t \in T, \forall i, j \in I, i \neq j
\end{aligned}
$$

$u_{i}^{t} \leq Q 1 t-\left(Q 1 t-q q_{i t}\right) \sum_{d=1}^{D} x_{i d}^{t} \quad \forall t \in T, \forall i \in I$,

$u u_{i}^{2 b t} \leq Q 2 t-\left(Q 2 t-e x_{i t}\right) \sum_{d=1}^{D} x_{d i}^{t} \quad \forall t \in T, \forall i \in I$

$u_{d}^{t}=\sum_{i=1}^{I} z_{i d t} q q_{i t} u_{d}^{t} \quad \forall t \in T, \forall d \in D$,

$u u_{d}^{t}=\sum_{i=1}^{I} z_{i d t} e x_{i t} \quad \forall t \in T, \forall d \in D$,

$q q_{i t}+\sum_{\substack{j=1 \\ i \neq j}}^{J} x_{i j}^{t} q q_{j t} \leq u_{i}^{t} \quad \forall t \in T, \forall i \in I$

$e x_{i t}+\sum_{\substack{j=1 \\ i \neq j}}^{J} x_{i j}^{t} e x_{j t} \leq u u_{i}^{t} \quad \forall t \in T, \forall i \in I$

$a t_{i t}+M\left(1-x_{d i}^{t}\right) \geq t t_{d i}\left(1+\varphi_{d i t}\right)$

$\forall t \in T, \forall i \in I, \forall d \in D$

$a t_{i t}-M\left(1-x_{d i}^{t}\right) \leq t t_{d i}\left(1+\varphi_{d i t}\right)$

$\forall t \in T, \forall i \in I, \forall d \in D$

$a t_{j t}+M\left(1-x_{i j}^{t}\right) \geq a t_{i t}+t t_{i j}\left(1+\varphi_{i j t}\right)$

$\forall t \in T, \forall i \in I, \forall j \in I$,

$a t_{j t}-M\left(1-x_{i j}^{t}\right) \leq a t_{i t}+t t_{i j}\left(1+\varphi_{i j t}\right)$

$\forall t \in T, \forall i \in I, \forall j \in I$,

$N f_{r t} \geq \theta \sum_{i=1}^{I} u u_{i}^{t} y x_{i r}^{t} / Q f \quad \forall t \in T, \forall r \in R$,

$N f_{r t} \leq \theta \sum_{i=1}^{I} u u_{i}^{t} y x_{i r}^{t} / Q f+1 \quad \forall t \in T, \forall r \underset{(34.2}{\in}$

$$
\begin{aligned}
& I_{i t}=I_{i t-1}+q q_{i t}-\widetilde{d_{i t}}-e x_{i t} \quad \forall t \in T, \forall i \in I, \\
& q q_{i y} \leq \operatorname{cap}_{i}-I_{i t-1} \quad \forall t \in T, \forall i \in I, \\
& I_{i t} \leq \operatorname{cap}_{i} \quad \forall t \in T, \forall i \in I, \\
& q_{i t t^{\prime}} \leq \operatorname{cap}_{i} \quad \forall t \in T, \forall i \in I, \\
& E x_{i t}=\sum_{k=t}^{T} q_{i(t-s l) k} \quad \forall t \in T, \forall i \in I, t \geq S L, \\
& E x_{i t}=0 \quad \forall t \in T, \forall i \in I, t \leq S L,
\end{aligned}
$$$$
\sum_{t^{\prime}=1}^{T} q_{i t t^{\prime}}=q q_{i t} \quad \forall t \in T, \forall i \in I,
$$$$
\sum_{t^{\prime} \leq t}^{T} q_{i t t^{\prime}}=0 \quad \forall t \in T, \forall i \in I,
$$$$
N l_{d t} \leq M y n_{d t} \quad \forall t \in T, \forall d \in D
$$$$
N f_{r t} \leq M y f_{r t} \quad \forall t \in T, \forall r \in R
$$

$y_{d t}^{g}, y_{r t}^{s}, w_{l d t}, z_{i d t}, x_{m n}^{t}, y x_{i r}^{t}, y n_{d t}, y f_{r t} \in\{0,1\}$,

$$
\begin{aligned}
& N l_{d t}, N f_{r t} \in Z_{+} \quad \text { on other domain, } \\
& V_{d t}, v e_{d t}, v l_{d t}, a t_{i t}, u_{i}^{t}, u u_{i}^{t}, I_{i t}, q_{i t t^{\prime}}, q q_{i t}, E x_{i t} \geq 0 .
\end{aligned}
$$

The first objective function minimizes the cost of transportation by lorries from plant to DCs in the outskirts, activating DCs with specified technology levels, violation of DC time windows, hiring of multicompartment trucks, multi-compartment truck transportation to/between retailers and to $\mathrm{RCs}$, operating $\mathrm{RCs}$, transportation of homogenous fleet to the CDC, and retailers' inventory holding minus the revenue of new products sold to the secondary market.

The second objective function minimizes environmental side effects including $\mathrm{CO}_{2}$ emission of activating/operating DCs / RCs, FCR, and $\mathrm{CO}_{2}$ emission of lorries, multi-compartment trucks, and homogeneous fleet. FCR of and $\mathrm{CO}_{2}$ emission from vehicles are formulated based on the traveled distance and weight of the carried loads. Xiao et al. [43] plotted real data and calculated the FCR of fully-loaded and unloaded trucks per kilometer. In Eq. (4), the FCR of partiallyloaded multi-compartment trucks was computed with linear interpolation by considering the summation of two variables, deliverable load $\left(u_{m}^{t}\right)$ and picked up load $\left(u u_{m}^{t}\right)$. 
The third objective function maximizes the utility of three main network stakeholders. A coefficient is assigned to each stakeholder that can be changed based on the prioritization of the company. The utility of retailers (customers) is formulated as the satisfaction level of service time in comparison to their desired time stated by fuzzy numbers. However, the utility of personnel is defined based on the distance of personnel from assigned DCs (Eq. (1)). The social objective function includes the social and economic impacts of activating/operating a $\mathrm{DC} / \mathrm{RC}$ with a specified technology level on economic development and job creation.

Constraints (6.1) and (6.2) specify the number of lorries moving from plant to active DCs. Constraint (7) avoids exceeding the capacity level of DCs in each period. Constraint (8) ensures that a DC can work with only one technology level. Constraint (9) calculates the demand assigned to an active DC. Constraint (10) vouches that each retailer be assigned to only one DC. Constraints (11.1) and (11.2) impose that a DC can be activated if there is a retailer assigned to it. Constraints (12.1) and (12.2) calculate the violation of the earliest and latest DC time windows, respectively. Constraint (13) states that only if a DC is activated, personnel can be allocated to it. Constraint (14) maintains the number of allocated personnel to a DC under maximum required personnel. Constraint (15) shows that each retailer should be connected to one of the retailers/ DCs. The flow balance of each node is guaranteed by Eq. (16). Constraints (17.1) to (17.3) assign operated RCs to the last retailer of routes if any expired products are loaded on the multi-compartment truck. If no expired product was picked up by trucks, the route would be open without assigning to RCs.

Constraints (18.1) and (18.2) impose that an RC can be active if there is a truck visiting it. Constraint (19) ensures that an RC is activated with just one technology level. Constraints (20)-(22) prevent the creation of unauthorized routes. The Location Routing Problem with Simultaneous Pickup and Delivery (LRPSPD) is subject to structural constraints. If a retailer is allocated to $\mathrm{DC} d$, it can be the last retailer of a route linked to $\mathrm{DC} d$ by a dummy arc (Constraint (20)), or the first retailer in a route starting from DC $d$ (Constraint (21)); or be connected to other retailers that are allocated to the same DC (Constraint (22)). Constraint (23) ensures the capacity limitation of RCs. Constraints (24) and (25) state the imbalance of delivery and pick-up flows between two nodes.

Constraints (26) and (27) mandate the remaining load of each compartment of trucks at each node. Also, Constraints (24) and (26) ascertain that fresh load be under the capacity of the compartment with cooling equipment. Constraints (25) and (27) put the second compartment capacity limitation on the amount of picked up expired products. Constraint (28) determines the fresh products needed at each active DC. Constraint (29) calculates the number of expired products gathered from all retailers, which are allocated to the same DC. Constraints (24) to (31) determine the limitations of auxiliary variables $u_{i}^{t}$ and $u u_{i}^{t}$.

Constraints (32.1) and (32.2) calculate the arrival time at the first retailer along each route. Constraints (33.1) and (33.2) calculate the arrival time at other retailers. The number of the needed homogenous fleet for transferring unusable perished products to the CDC is calculated by Constraints (34.1) and (34.2). For each retailer, Constraint (35) balances among the inventory levels of the current and previous period, the demand, received products, and expired products of the current period. Constraints (36.1), (36.2), and (36.3) ensure that the inventory level of a retailer does not exceed its capacity level. The number of expired products is calculated by Constraints (37.1) and (37.2) based on the violation of holding duration from the product's shelf life. Constraint (38) calculates the total quantity of received products by each retailer periodically. Constraint (39) prohibits back-ordering demands to avoid customer dissatisfaction. Constraints (40) and (41) determine variables $y n_{d t}$ and $y f_{r t}$ based on their definition. Finally, Constraint (42) determines the variable's domain.

\subsubsection{Linearization of multiplying a binary variable by a continuous variable}

This multiplicative statements appeared in the objective functions (e.g., $N l_{d t} . y n_{d t}$ and $N f_{r t} . y f_{r t}$ in Eq. (4) and, also, some constraints (e.g., (9), (17.1), (23), (24), (25), (26), (27), (29), (30), (34.1), and (34.2)). If a continuous variable $(Q)$ is multiplied by a binary variable $(x)$, the multiplicative statement should be replaced by a new continuous variable $y$ (i.e., $y=Q x$ ) and the following constraints should be added to the model:

$$
\begin{aligned}
& y \leq Q \leq M x, \\
& y \leq M x, \\
& y \geq Q-M(1-x), \\
& Q \geq 0, \quad x \in\{0,1\}, \quad y \geq 0 .
\end{aligned}
$$

3.1.2. Linearization of multiple breakpoint functions Regarding the fuzzy desired time window of retailer $i$ in period $t, t \widetilde{w}_{i t}$, the utility function of retailer $i$ in period $t, u c_{i t}$, can be stated as a piecewise linear function of arrival time, $a t_{i t}$, as follows: 


$$
\begin{aligned}
& u c_{i t}= \\
& \begin{cases}0 & a t_{i t}<t w 1_{i t} \text { orat } \\
\frac{a t_{i t}}{t w 2_{i t}-t w 1_{i t}}-\frac{t w 1_{i t}}{t w 2_{i t}-t w 1_{i t}} & t w 1_{i t} \leq a t_{i t}<t w 2_{i t} \\
1 & t w 2_{i t} \leq a t_{i t} \leq t w 3_{i t} \\
\frac{t w 4_{i t}}{t w 4_{i t}-t w 3_{i t}}-\frac{a t_{i t}}{t w 4_{i t}-t w 3_{i t}} & t w 3_{i t}<a t_{i t} \leq t w 4_{i t}\end{cases}
\end{aligned}
$$

According to Al-e-hashem et al. [44], by defining a continuous variable $a t t_{b p}$ it and a binary variable $b b_{b p}$, where index $b p$ shows each linear piece of the utility function, the multiple breakpoint functions (44) can be converted into the following single function:

$$
\begin{aligned}
u c_{i t}= & a t t_{2 i t} \frac{1}{t w 2_{i t}-t w 1_{i t}}-b b_{2} \frac{t w 1_{i t}}{t w 2_{i t}-t w 1_{i t}} \\
& +b b_{3} \times 1-a t t_{4 i t} \frac{1}{t w 4_{i t}-t w 3_{i t}} \\
& +b b_{4} \frac{t w 4_{i t}}{t w 4_{i t}-t w 3_{i t}} .
\end{aligned}
$$

Also, the following equations should be added to the model:

$$
\begin{array}{ll}
-M b b_{1} \leq a t t_{1 i t} \leq t w 1_{i t} b b_{1} & \forall t \in T, \forall i \in I, \\
t w 1_{i t} b b_{2} \leq a t t_{2 i t} \leq t w 2_{i t} b b_{2} & \forall t \in T, \forall i \in I, \\
t w 2_{i t} b b_{3} \leq a t t_{3 i t} \leq t w 3_{i t} b b_{3} & \forall t \in T, \forall i \in I, \\
t w 3_{i t} b b_{4} \leq a t t_{4 i t} \leq t w 4_{i t} b b_{4} & \forall t \in T, \forall i \in I, \\
t w 4_{i t} b b_{5} \leq a t t_{5 i t} \leq M b b_{5} & \forall t \in T, \forall i \in I, \\
\sum_{b P=1}^{B P} a t t_{b p i t}=a t_{i t} & \forall t \in T, \forall i \in I, \forall d \in D, \\
\sum_{b p=1}^{B P} b b_{b p}=1, & \\
b b_{b p} \in\{0,1\}, a t t_{b p i t} \geq 0 & \forall t \in T, \forall i \in I, \forall b p \in B P .
\end{array}
$$

Other multi breakpoint linear functions in the developed mathematical model (e.g., the utility of personnel) can be converted into a single linear statement similarly.

\subsection{Dealing with fuzzy uncertainty}

Because of the competitive market, demand is vague and uncertain. Since no distributional data is available in many cases, demand is stated by a trapezoidal fuzzy number, i.e., $\tilde{d}_{i t}=\left(d_{i t_{(1)}}, d_{i t_{(2)}}, d_{i t_{(3)}}, d_{i t_{(4)}}\right)$. Here, the Basic Possibilistic Chance-Constrained Programming (BPCPP) approach is applied for defuzzification. Regarding BPCPP, the expected value is used for uncertain parameters in the objective function. To transform constraints to crisp statements, the necessity measure $(N e c)$ is applied [45]. Constraint (35) is replaced with two inequalities below:

$$
\begin{aligned}
& N e c\left\{I_{i t} \leq I_{i t-1}+q q_{i t}-\widetilde{d_{i t}}-e x_{i t}\right\} \geq \beta \\
& \forall t \in T, \forall i \in I, \\
& N e c\left\{I_{i t} \geq I_{i t-1}+q q_{i t}-\widetilde{d_{i t}}-e x_{i t}\right\} \geq \beta \\
& \forall t \in T, \forall i \in I,
\end{aligned}
$$

where $0.5<\beta<1$ is the minimum confidence level of chance constraints. Finally, the two above constraints are replaced with Constraints (48.1) and (48.2) as follows:

$$
\begin{aligned}
& I_{i t} \leq I_{i t-1}+q q_{i t}-\left((1-\beta) d_{i t_{(2)}}+\beta d_{i t_{(1)}}\right)-e x_{i t} \\
& \forall t \in T, \forall i \in I \\
& I_{i t} \geq I_{i t-1}+q q_{i t}-\left((1-\beta) d_{i t_{(3)}}+\beta d_{i t_{(4)}}\right)-e x_{i t} \\
& \forall t \in T, \forall i \in I .
\end{aligned}
$$

In the rest of this study, $\beta$ is set to 0.8 .

\section{Solution approach}

In this section, the developed model is first solved by the exact method. The multi-objective model is turned into a single-objective one by the $\mathrm{TH}$ method [46]. Then, two meta-heuristics are developed to find nearoptimal solutions in a reasonable time, especially for medium- and large-sized cases.

Ahmadi Javid and Azad [32] found that the LRIP, which is a simple form of the model presented in Section 3 , belonged to the NP-complete class with a nonpolynomial order of solving time, without considering backward flow, recycling stage, and product shelf life. Devika et al. [5] also formulated a CLSC that could be a sub-problem of our model without perishability and some decision levels, and acknowledged the NPcompleteness of the studied problem. Thus, the LRIP model considered in this paper is classified as an NPcomplete problem since it is a comprehensive version of the problems mentioned above. Because of the long solving time of the exact method, two meta-heuristics namely Non-Dominated Sorting Genetic Algorithm-II (NSGA-II) and a hybrid multi-objective algorithm are developed and compared based on the multi-objective performance metrics to deal with the problem in a reasonable solving time. Moreover, some heuristic procedures are tailored for solution representation to achieve a feasible solution by taking all constraints into account. A core i7 laptop does all computations with $12 \mathrm{~GB}$ RAM and $2.6 \mathrm{GHz}$ CPU on a 64 -bit Windows. 


\subsection{Model validation and application}

The developed model is solved by CPLEX solver of GAMS software version 24.8.3 as powerful software in solving MILP problems. For model validation, it is implemented for a real-case study. There is an industrial bread plant in a neighboring city of Tehran. There are two DCs in the outskirt for unloading products from big lorries to smaller two-compartment trucks. There are five retailers in the city. Two RCs in the city are ready to recycle expired products. The DCs and RCs should decide on their applied technology to be solar or electricity. The planning horizon is three periods. Therefore, the size of the case study is $|D| \times|G| \times|I| \times|R| \times|S| \times|L| \times|T|=2 \times 2 \times 5 \times 2 \times$ $2 \times 10 \times 3$. The extent of other parameters is stated in Subsection 4.6 used for generating test problems.

The three single-objective problems by each ob- jective function are solved for showing the conflict among three objective functions [11]. The results of these problems are reported in Table 3. In this table, retailers are shown by numbers 3 to 7 . The first part of the table shows the optimal solution obtained in the presence of the economic objective function. In this case, because of selling secondary products, a significant number of expired products are delivered to the RCs. Moreover, a limited number of DCs and RCs are opened with a cheap technology level even though this technology level has high environmental side effects. Activation of a few DCs/RCs prevents job creation through opening DCs/RCs. Therefore, the supply chain is planned without attention to its environmental and social impacts.

In the second part of Table 3 , when the problem is solved in the presence of the green objective function,

Table 3. Optimal solution of the case study by considering only one objective function.

\begin{tabular}{|c|c|c|c|c|c|c|c|c|}
\hline & Period & Plant & NL & $\mathrm{DC}$ & $\begin{array}{l}\text { Order of retailers } \\
\text { in a route }\end{array}$ & $\mathbf{R C}$ & Nf & $\mathrm{CDC}$ \\
\hline \multirow{6}{*}{ 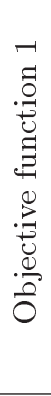 } & \multirow[t]{2}{*}{1} & \multirow[t]{2}{*}{1} & 1 & $\begin{array}{c}1 \checkmark \\
\{g=2\}\end{array}$ & $\begin{array}{c}1 \gg 5>3>4 \gg 1 \\
1 \gg 7>6 \gg 1\end{array}$ & 1 & - & \multirow{2}{*}{1} \\
\hline & & & - & 2 & - & 2 & - & \\
\hline & \multirow{2}{*}{2} & \multirow{2}{*}{1} & 1 & $\begin{array}{c}1 \checkmark \\
\{g=2\}\end{array}$ & $\begin{array}{c}1 \gg 4>3>7 \gg 1 \\
1 \gg 5>6 \gg 1\end{array}$ & 1 & - & \multirow{2}{*}{1} \\
\hline & & & - & 2 & - & 2 & - & \\
\hline & \multirow{2}{*}{3} & \multirow{2}{*}{1} & 1 & $\begin{array}{c}1 \checkmark \\
\{g=2\}\end{array}$ & $\begin{array}{c}1 \gg 4>3>7 \gg(\mathrm{RC}: 1) \\
1 \gg 5>6 \gg(\mathrm{RC}: 1)\end{array}$ & $\begin{array}{c}1 \checkmark \\
\{\mathrm{s}=2\}\end{array}$ & 1 & \multirow{2}{*}{1} \\
\hline & & & - & 2 & - & 2 & - & \\
\hline \multirow{6}{*}{ 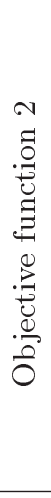 } & \multirow[t]{2}{*}{1} & \multirow[t]{2}{*}{1} & 1 & $\begin{array}{c}1 \checkmark \\
\{g=1\}\end{array}$ & $1 \gg 5>4 \gg 1$ & 1 & - & \multirow[t]{2}{*}{1} \\
\hline & & & 1 & $\begin{array}{c}2 \checkmark \\
\{g=1\}\end{array}$ & $2 \gg 6>7>3 \gg 2$ & 2 & - & \\
\hline & \multirow{2}{*}{2} & \multirow{2}{*}{1} & 1 & $\begin{array}{c}1 \checkmark \\
\{g=1\}\end{array}$ & $1 \gg 7>6>5 \gg 1$ & 1 & - & \multirow{2}{*}{1} \\
\hline & & & 1 & $\begin{array}{c}2 \checkmark \\
\{g=1\}\end{array}$ & $2 \gg 4>3 \gg 2$ & 2 & - & \\
\hline & \multirow[t]{2}{*}{3} & \multirow[t]{2}{*}{1} & 1 & $\begin{array}{c}1 \checkmark \\
\{g=1\}\end{array}$ & $1 \gg 5>6>7>3>4 \gg 1$ & 1 & - & \multirow[t]{2}{*}{1} \\
\hline & & & - & 2 & - & 2 & - & \\
\hline \multirow{6}{*}{ 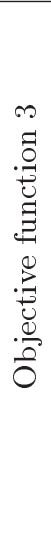 } & \multirow[t]{2}{*}{1} & \multirow[t]{2}{*}{1} & 1 & $\begin{array}{c}1 \checkmark \\
\{g=1\}\end{array}$ & $1 \gg 7>6 \gg 1$ & 1 & - & \multirow[t]{2}{*}{1} \\
\hline & & & 1 & $\begin{array}{c}2 \checkmark \\
\{g=1\}\end{array}$ & $2 \gg 3>4>5 \gg 2$ & 2 & - & \\
\hline & \multirow[t]{2}{*}{2} & \multirow[t]{2}{*}{1} & 1 & $\begin{array}{c}1 \checkmark \\
\{g=1\}\end{array}$ & $1 \gg 7>6 \gg 1$ & 1 & - & \multirow[t]{2}{*}{1} \\
\hline & & & 1 & $\begin{array}{c}2 \checkmark \\
\{g=1\}\end{array}$ & $2 \gg 3>4>5 \gg 2$ & 2 & - & \\
\hline & \multirow[t]{2}{*}{3} & \multirow[t]{2}{*}{1} & 1 & $\begin{array}{c}1 \checkmark \\
g=1\}\end{array}$ & $1 \gg 7 \gg(\mathrm{RC}: 2)$ & $\begin{array}{c}1 \checkmark \\
\{s=1\}\end{array}$ & 1 & \multirow[t]{2}{*}{1} \\
\hline & & & 1 & $\begin{array}{c}2 \checkmark \\
\{g=1\}\end{array}$ & $2 \gg 3>6>4>5 \gg(\mathrm{RC}: 1)$ & $\begin{array}{c}2 \checkmark \\
\{\mathrm{s}=1\}\end{array}$ & 1 & \\
\hline
\end{tabular}


there is no need to store excessive products and then, sell expired products to the RCs, which cause GHG emissions. Plus, DCs utilizes nature-friendly technology; however, it is expensive.

Based on the last part of Table 3, which shows the optimal solution in the presence of only the social objective function, most of the DCs/RCs are operated. However, it is costly and may not be environmentfriendly; it causes job creation and economic growth in the local regions. In this case, the length of the routes is more uniform because of emphasizing the time windows of the retailers. In this table, the distinction among optimal solutions by considering different goals confirms the conflict of goals. Therefore, the necessity of considering different objective functions simultaneously and solving a multi-objective problem is verified.

\subsection{Turning the multi-objective problem to a single one by the TH method}

One of the main methods for solving MOPs that gives efficient balanced and unbalanced solutions is the $\mathrm{TH}$ method [46]. This method is a fuzzy-based method that deals with the MOP in a way that maximizes the satisfaction degree of objective functions [41]. After determining the Positive Ideal Solution (PIS), $\left(f_{i}^{P I S}, x_{i}^{P I S}\right)$, and the Negative Ideal Solution (NIS), $\left(f_{i}^{N I S}, x_{i}^{N I S}\right)$, the satisfaction degree of a minimization objective function is calculated by:

$$
\mu_{i}(x)=\left\{\begin{array}{lll}
1 & \text { If } & f_{i}<f_{i}^{P I S} \\
\frac{f_{i}^{N I S}-f_{i}}{f_{i}^{N I S}-f_{i}^{P I S}} & \text { If } \quad f_{i}^{P I S} \leq f_{i} \leq f_{i}^{N I S} \\
0 & \text { If } & f_{i}>f_{i}^{N I S}
\end{array}\right.
$$

The satisfaction degree for maximization objective functions is formulated as Eq. (50):

$$
\mu_{i}(x)=\left\{\begin{array}{lll}
1 & \text { If } & f_{i}>f_{i}^{P I S} \\
\frac{f_{i}-f_{i}^{N I S}}{f_{i}^{P I S}-f_{i}^{N I S}} & \text { If } & f_{i}^{N I S} \leq f_{i} \leq f_{i}^{P I S} \\
0 & \text { If } & f_{i}<f_{i}^{N I S}
\end{array}\right.
$$

In the developed model, three objective functions are targeted. The values of the PIS are reported by solving three single objective problems in Table 4 (payoff table), while the values of the NIS are specified to be approximate that result from having more than two objective functions.

After determining $\mu_{i}(x)$ for all objectives, the aggregate function of the $\mathrm{TH}$ method for turning MOP into a single-objective problem is formulated by:

$$
\begin{aligned}
& \operatorname{Max} \varphi \beta_{0}+(1-\varphi) \sum_{k} \theta_{k} \mu_{k}(x), \\
& \mu_{k}(x) \geq \beta_{0} \quad \forall k, x \in F_{x}
\end{aligned}
$$

where $\beta_{0} \in[0,1]$ and $\beta_{0}=\left\{\mu_{k}(x)\right\} . \varphi$ is the coefficient of compensation, which controls the minimum satisfaction level of the objectives $\left(\beta_{0}\right)$ besides the compromise degree among the objectives. Moreover, $\theta_{k}$ shows the relative importance of the $k$ th objective function determined by the decision-maker based on the preferences such that $\sum_{k} \theta_{k}=1, \theta_{k}>0$.

The optimal solution of the TH method for $\theta_{1}=$ $0.4, \theta_{2}=0.2, \theta_{3}=0.4, \varphi=0.55$ is reported in Table 5 . To show the solution better, a schematic view is also presented in Figure 2.

\begin{tabular}{|c|c|c|c|c|c|c|c|}
\hline Period & Plant & NL & DC & $\begin{array}{l}\text { Order of retailers } \\
\text { in a route }\end{array}$ & $\mathbf{R C}$ & Nf & CDC \\
\hline \multirow{2}{*}{1} & \multirow{2}{*}{1} & 1 & $\begin{array}{c}1 \checkmark \\
\{g=1\}\end{array}$ & $\begin{array}{c}1 \gg 4>6 \gg 1 \\
1 \gg 5>7>3 \gg 1\end{array}$ & 1 & - & \multirow{2}{*}{1} \\
\hline & & - & 2 & - & 2 & - & \\
\hline \multirow{2}{*}{2} & \multirow{2}{*}{1} & 1 & $\begin{array}{c}1 \checkmark \\
\{g=1\}\end{array}$ & $\begin{array}{c}1 \gg 3>7 \gg 1 \\
1 \gg 5>6>4 \gg 1\end{array}$ & 1 & - & \multirow{2}{*}{1} \\
\hline & & - & 2 & - & 2 & - & \\
\hline \multirow{2}{*}{3} & \multirow{2}{*}{1} & 1 & $\begin{array}{c}1 \checkmark \\
\{g=1\}\end{array}$ & $\begin{array}{c}1 \gg 4>3>7 \gg(\mathrm{RC}: 1) \\
1 \gg 5>6 \gg(\mathrm{RC}: 1)\end{array}$ & $\begin{array}{c}1 \checkmark \\
\{\mathrm{s}=1\}\end{array}$ & 1 & \multirow{2}{*}{1} \\
\hline & & - & 2 & - & 2 & - & \\
\hline
\end{tabular}

Table 4. Pay-off table.

\begin{tabular}{ccccc}
\hline $\boldsymbol{x}_{\boldsymbol{i}}^{*}$ & Desired orientation of $\boldsymbol{f}_{\boldsymbol{i}}$ & $\boldsymbol{f}_{\mathbf{1}}$ & $\boldsymbol{f}_{\mathbf{2}}$ & $\boldsymbol{f}_{\mathbf{3}}$ \\
\hline$x_{1}^{*}$ & $\operatorname{Min} f_{1}$ & $f_{1}^{P I S^{*}}=7254.767$ & $f_{2}\left(x_{1}^{*}\right)=6449.520$ & $f_{3}\left(x_{1}^{*}\right)=30.2386$ \\
$x_{2}^{*}$ & $\operatorname{Min} f_{2}$ & $f_{1}\left(x_{2}^{*}\right)=12056.5$ & $\left(f_{2}^{P I S}\right)^{*}=4668.214$ & $f_{3}\left(x_{2}^{*}\right)=38.7702$ \\
$x_{3}^{*}$ & $\operatorname{Max} f_{3}$ & $f_{1}\left(x_{3}^{*}\right)=18261.3$ & $f_{2}\left(x_{3}^{*}\right)=10449.519$ & $\left(f_{3}^{P I S}\right)^{*}=59.952$ \\
\hline$f_{i}^{N I S}$ & $\operatorname{Max}\left\{f_{1,2}\left(x^{*}\right)\right\}$ & 18261.3 & 10449.519 & 30.2386 \\
& $\operatorname{Min}\left\{f_{3}\left(x^{*}\right)\right\}$ & & & \\
\hline
\end{tabular}

Table 5. Optimal solution of the case study by the TH method, $\theta_{1}=0.4, \theta_{2}=0.2, \theta_{3}=0.4, \varphi=0.55$. 

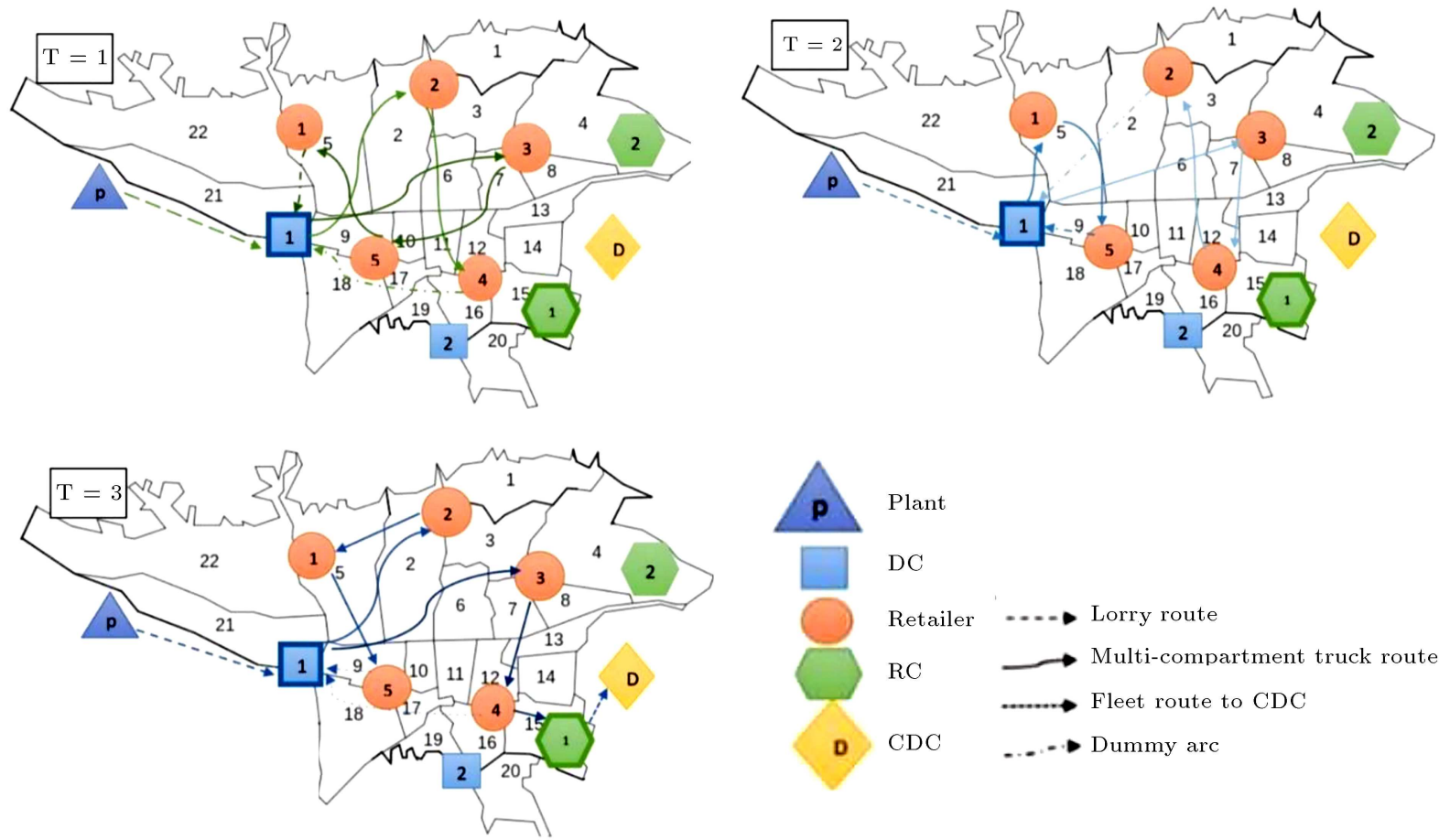

Figure 2. Solution obtained by the TH method for $\varphi=0.55$.

Table 6. Pareto-optimal solutions of the TH method.

\begin{tabular}{|c|c|c|c|c|c|c|c|}
\hline \multirow{6}{*}{$\begin{array}{l} \\
\times \\
10 \\
\times \\
\times \\
\times \\
\times \\
N\end{array}$} & \multirow{6}{*}{$\begin{array}{c}\infty \\
\times \\
0 \\
0 \\
\times \\
\times \\
\sim \\
\times \\
\sim\end{array}$} & $\varphi$ & Objective 1 & Objective 2 & Objective 3 & Satisfaction degree & Computational time \\
\hline & & 0.55 & 10518.43 & 6362.177 & 67.9 & $\mu_{T}(f)=0.805$ & 14400 \\
\hline & & 0.65 & 10178.19 & 6193.62 & 61.03 & $\mu_{T}(f)=0.788$ & 14550 \\
\hline & & 0.75 & 9837.953 & 6025.061 & 54.166 & $\mu_{T}(f)=0.769$ & 14500 \\
\hline & & 0.85 & 9830.153 & 6020.403 & 53.661 & $\mu_{T}(f)=0.767$ & 14250 \\
\hline & & 0.95 & 9820.352 & 6015.816 & 53.156 & $\mu_{T}(f)=0.767$ & 14300 \\
\hline \multicolumn{3}{|c|}{ Avg. } & 10037.02 & 6123.415 & 57.9726 & 0.7794 & 14400 \\
\hline
\end{tabular}

The Pareto solutions are obtained by different values of $\varphi$, including $0.55,0.65,0.75,0.85,0.95$, presented in Table 6 . As shown in the last column of this table, the computation time of the exact method for even a small problem is very long, let alone the medium- or large-sized ones. Even the time required for estimating $f_{i}^{N I S}$, which is necessary for the $\mathrm{TH}$ method, is ignored in the calculation. Therefore, two meta-heuristic algorithms are developed.

\subsection{Non-dominated Sorting Genetic Algorithm-II (NSGA-II)}

NSGA-II is a population-based meta-heuristic algorithm [47] that finds a set of non-dominated solutions (called a Pareto front) using specific sorting and selection methods. Due to the domination concept, $x$ dominates $y$ if and only if in all objectives, $x$ is not worse than $y$ and at least in one of the objectives, $x$ is better than $y[47]$. The steps of the NSGA-II procedure are as follows:

Phase 1: Initialization:

Step 1. Generating the initial population;

Step 2. Calculating fitness (objective) functions for each solution;

Step 3. Assigning a rank to each chromosome based on the concept of domination for sorting purposes. For sorting chromosomes with the same rank, a Crowding Distance (CD) measure, which declares an estimate of the solution's density surrounding a specific solution, is used. $C D$ is equal to the average distance of two neighboring solutions of a specific solution. CD measure prefers the uniformly spread of solutions in the objective space and prioritizes solutions with lower crowding distance. After sorting, the best solutions will be selected as parents by selection methods. 


\section{Phase 2: Main loop:}

Step 1. Employing the crossover operator with crossover rate, $P_{c}$, and the mutation operator with mutation rate, $P_{m}$; the next population, $Q_{t}$, called offspring population with size $N$ is generated;

Step 2. Combining the offspring with parents organizes the union population $R_{t}$;

Step 3. Calculating the fitness value of the union population $R_{t}$;

Step 4. Applying non-dominated sorting concerning domination and crowding distance criteria, in order. The first $N$ solutions from the sorted union population $R_{t}$ are selected as the best solutions to form the population $P_{t+1}$ at the next iteration.

The above steps will be accomplished until reaching the stopping criterion.

\subsection{A new hybrid multi-objective meta-heuristic algorithm}

The NSGA-II does not have a memory to take advantage of the learning. Thus, a new hybrid algorithm is developed by combining the NSGA-II with MultiObjective Particle Swarm Optimization (MOPSO), which has memory and self-learning ability [48].

The Particle Swarm Optimization (PSO) algorithm for single-objective problems is inspired by the movement of folk birds for finding food. In 2006, the multi-objective version of PSO, named MOPSO, was proposed by Reyes-sierra and Coello [48]. In this population-based algorithm, each particle (equivalent to the chromosome of NSGA-II), uses its personal best memory $\left(x_{\text {pbest }}\right)$ and global best memory $\left(x_{\text {gbest }}\right)$ of the swarm to find the best movement for the flight route. It means that each particle uses the knowledge of personal and group intelligence for learning.

The velocity of each particle $p$ for the $i$ th dimension at iteration $t, v_{p i}(t)$, is calculated by:

$$
\begin{aligned}
v_{p i}(t)= & w v_{p i}(t-1)+c_{1} r_{1}\left(x_{p b e s t}(t)-x_{p i}(t)\right) \\
& +c_{2} r_{2}\left(x_{\text {gbest }}(t)-x_{p i}(t)\right)
\end{aligned}
$$

where $x_{\text {pbest }}$ is the personal best position of a particle so far and $x_{\text {gbest }}$ is the position of the best group (swarm) particle. $w$ is the inertia weight that maintains the impact of the last velocity on the new velocity. $C_{1}$ and $C_{2}$ are cognitive and social learning coefficients associated with the particle success and neighborhood success, respectively, to handle their influence on the new velocity. $r_{1}$ and $r_{2}$ are random numbers on $[0,1]$. The position of each particle $p$ for the $i$ th dimension at iteration $t, x_{p i}(t)$, is calculated by:

$$
x_{p i}(t)=x_{p i}(t-1)+v_{p i}(t) .
$$

With these explanations, the hybridization process can be illuminated, in which the NSGA-II and MOPSO are integrated hierarchically, as shown in Figure 3. The NSGA-II is first run and, then, the

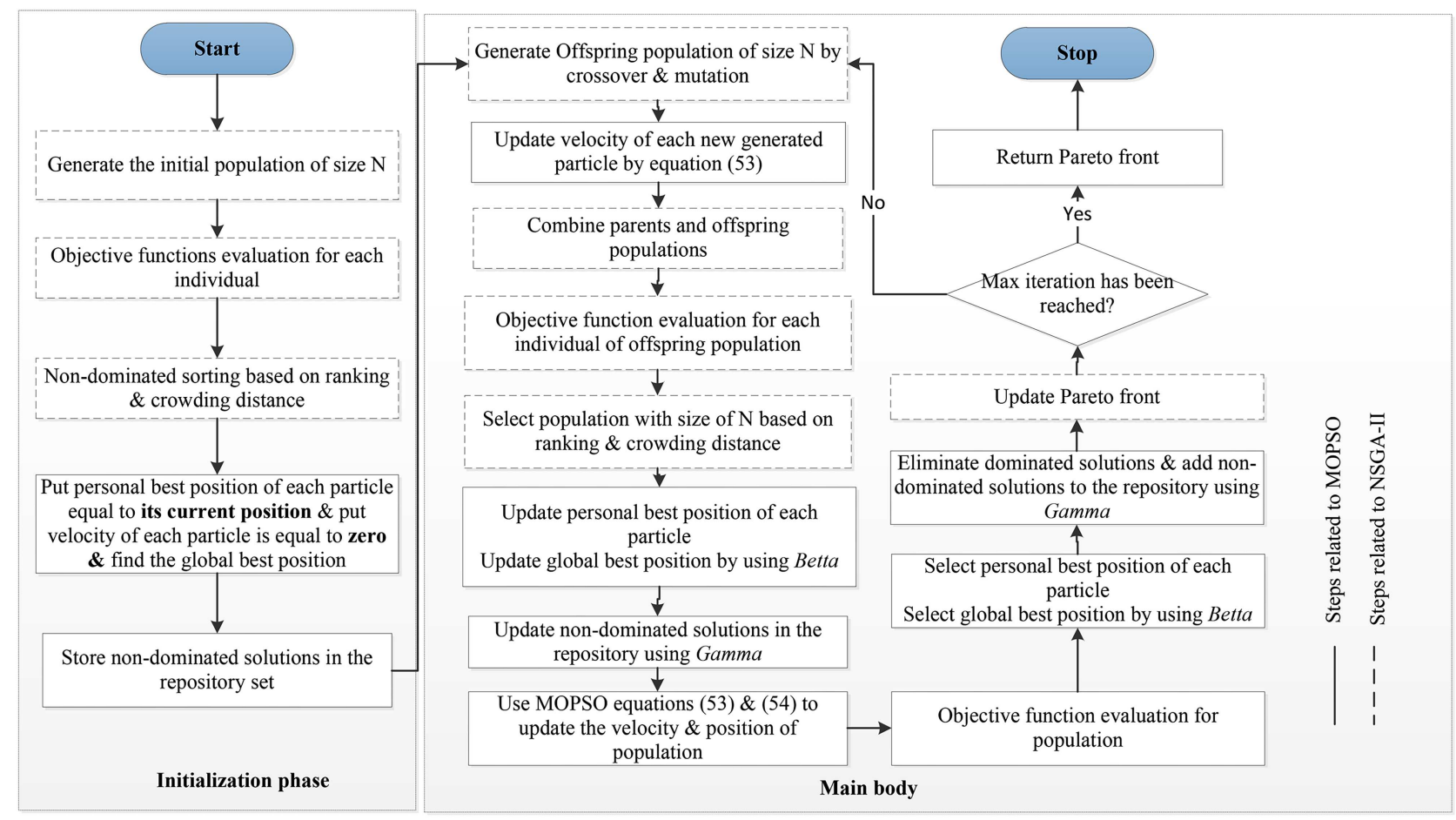

Figure 3. Proposed hybrid NSGA-II-MOPSO algorithm. 
solutions are imported to the MOPSO algorithm as an initial swarm to be improved by it.

The initialization phase: The initial population is generated using NSGA-II. The non-dominated solutions are determined by the NSGA-II set as initial particles of MOPSO. Then, the personal best positions and velocities of initial solutions are set to their current position and zero, in order. Finally, the non-dominated solutions are saved in a repository set of MOPSO as initial repository members.

The main body: The main loop starts with the NSGA-II. After generating offspring by crossover and mutation operators, the velocity of each generated solution is updated. Then, the union population is formed and ranked based on domination and CD criteria. The resulting non-dominated population will be the input of the MOPSO algorithm. The best position of each particle is selected as the personal best position. The best position of non-dominated solutions as leaders of the swarm is selected as the global best position. If the number of non-dominated solutions is more than the capacity of the repository, the Beta parameter is used as a leader selection pressure [48] to choose leaders from the repository. Then, the steps of the MOPSO algorithm run sequentially. The velocity vector of each particle and its position will be updated by Eqs. (53) and (54), respectively. Afterward, the fitness of each swarm particle is evaluated, and new non-dominated solutions are added to the repository of non-dominated solutions. Subsequently, dominated solutions are eliminated to amend the repository set. If the number of candidate particles for saving in the repository is more than the capacity of the repository, the Gamma parameter is used as a deletion pressure.
Finally, a new iteration will start if the stopping criterion is not satisfied.

\subsection{Initial solution representation}

This study attempts to find feasible solutions from the beginning. Since the model has several categories of decision variables, several representation codes, including matrixes/cell arrays, are used to generate the initial solution.

- The first matrix: $|T| \times|N+D-1|$ matrix is used to determine the open DCs and allocate retailers to them. For each period (each row), the matrix is filled with a permutation of the number of retailers and DCs minus one. How to extract activated DCs and assign retailers to them is visible in two steps given in Figure 4.

The capacity allocated to each active DC should be controlled periodically, which is equal to the total demand of retailers allocated to that DC. The number of trucks needed to deliver the products from the plant to $\operatorname{DCs}\left(N l_{d t}\right)$ is derived from the division of assigned capacity to the truck capacity and rounding up the quotient. It is possible to calculate the violation penalty of the soft time windows $\left(V e_{d t}, V l_{d t}\right)$ for each DC by identifying operated DCs and traveling time from the plant to them.

- The second matrix: To decide on the technology applied in each DC, a matrix of $1 \times|D|$, filled with integers from [1, $G$ (the number of technology levels for DCs)] is randomly produced, as demonstrated in Figure 5. Thus, the binary variables $y_{d t}^{g}$ can be specified.

Now, by considering the demand of assigned retailers to a DC as well as the capacity of the refrig-

$\mathrm{T}\left\{\begin{array}{c|c|c|c|c|c|c|c|c|c|c|}\hline \multicolumn{10}{|c|}{\text { DC no. } 2} & \multicolumn{10}{|c|}{\text { DC no. } 1} \\ \hline 6 & 3 & 11 & 7 & 8 & 5 & 1 & 2 & 4 & 9 & 10 \\ \hline 11 & 5 & 6 & 3 & 10 & 8 & 4 & 7 & 2 & 9 & 1 \\ \hline 2 & 3 & 11 & 8 & 6 & 4 & 10 & 1 & 7 & 5 & 9 \\ \hline\end{array}\right.$

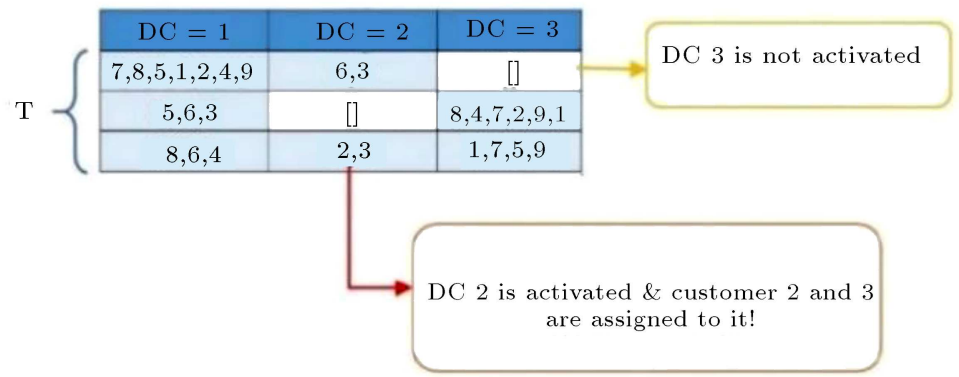

Figure 4. First matrix to present a solution. 


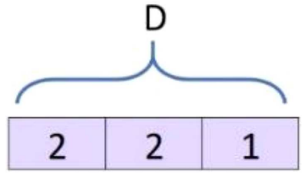

Figure 5. Second matrix to select the DC's technology.

erated and normal part of the multi-compartment truck, the routes beginning from each DC can be determined via the pseudo-code presented in Figure 6.

By identifying the routes, it is easy to calculate the arrival time at each retailer $\left(a t_{i t}\right)$.

- The third matrix with changing number of columns (cell array): If a truck carries expired products at the end of an open route, the route should be connected to RC. For this purpose, a cell array of $|T| \times|n T|$ is used where $n T$ shows the number of routes formed in period $T$. Since $n T$ may vary over periods, cell arrays are used instead of a matrix. The cell array is randomly filled with integers from $[1, R]$, as shown in Figure 7 .

To maintain the feasibility of the solution, the capacity assigned to each operated $\mathrm{RC}$ in each period is calculated continuously. As long as the allocated capacity is more than the predetermined capacity of RC, it continues to generate that row of cell arrays randomly. Whenever the last retailer in a route and the $\mathrm{RC}$ assigned to it are specified, the binary variables $y x_{i r}^{t}$ can be determined.

- The fourth matrix: To decide on the technology used in each RC, a matrix of $1 \times|R|$ is considered filled by integers from [1, $S$ (the number of technology levels for RCs)] randomly. An example is shown

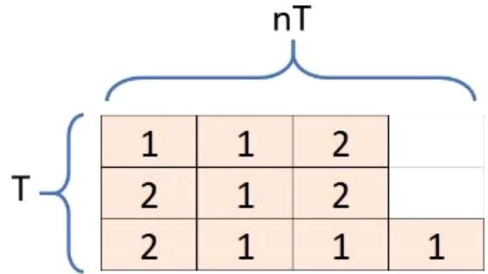

Figure 7. Third cell array to connect eligible routes to RCs.

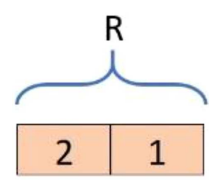

Figure 8. Fourth matrix to select the RC's technology.

in Figure 8. Therefore, the binary variables $y_{r t}^{s}$ can be specified.

The number of expired products shipped to each RC is determined. By dividing $\theta \%$ by the fleet capacity, the number of required fleets, $N f_{r t}$, to transfer unusable products from an operated RC to the CDC is obtained.

- The fifth matrix: To allocate personnel to active DCs, first personnel numbers are put on a permutation matrix for each period. Then, it starts with the first active DC and assigns the first $r p_{d g}$ cells of the matrix to that DC. Similarly, the personnel required for other active DCs are allocated. The matrix with the size of $|T| \times|L|$ is used for this process shown in Figure 9 . In this way, the binary variables $w_{l d t}$ can be determined.

Random numbers are applied to determine inventory decision variables. Before generating the matrices

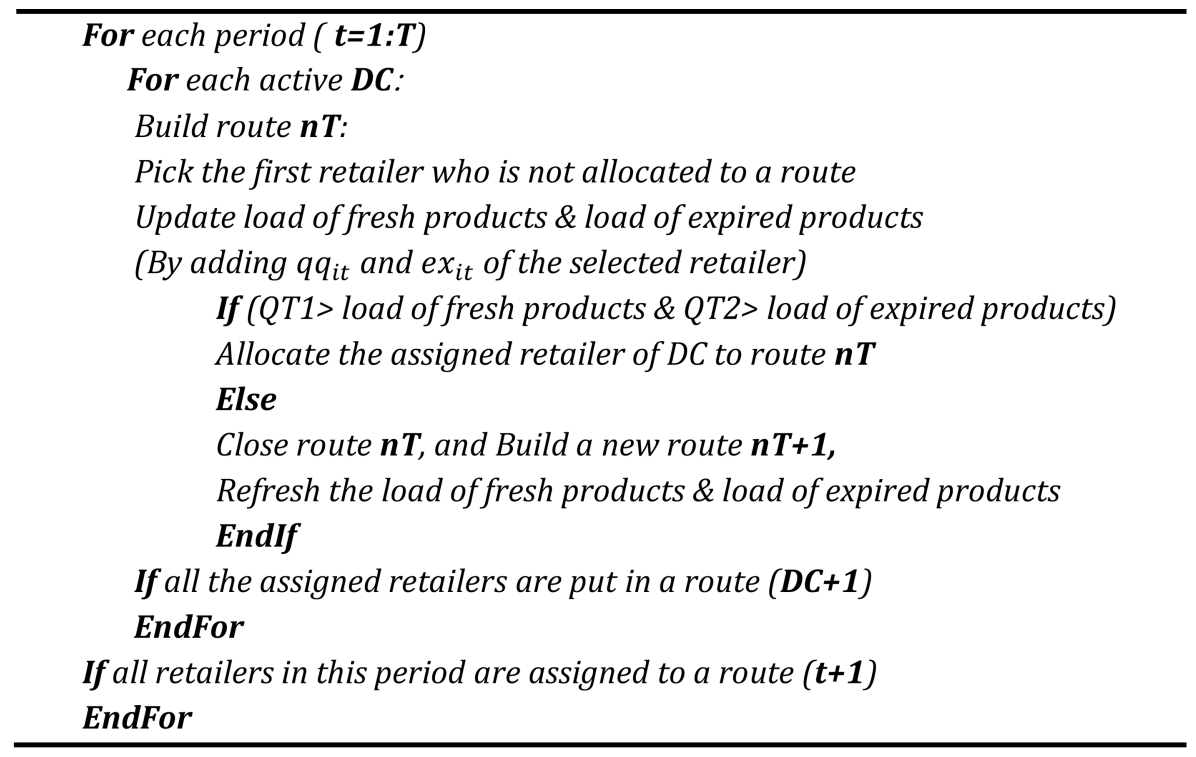

Figure 6. Pseudo code to specify routes. 


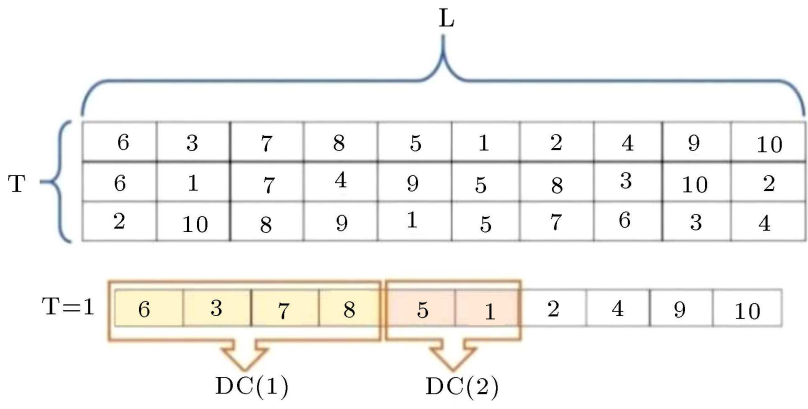

Figure 9. Process of personnel allocation.

mentioned above, the number of products that must be delivered to the retailers in each period, including the product needed for the current period and a random percentage of the products for the next periods, $q q_{i t}$ and $q_{i t}$, should be determined. Two main limitations namely the retailer's capacity and the product's shelf life are controlled in generating $q q_{i t}$ and $q_{i t}$. Moreover, the expired products at the end of each period $\left(e x_{i t}\right)$ can be calculated considering $q q_{i t}, q_{i t}$ and the product's shelf life.

The single-point crossover and inversion mutation are used to generate offspring. These operators are described by Rabbani et al. [18] in detail. In the hybrid algorithm, the MOPSO algorithm with continuous solution space is merged. Thus, a continuous equivalent for the initial solution is required. Instead of permutation, continuous numbers with uniform distribution in $[0,1]$, sorted from small to large, are ranked for further use. Furthermore, the second to fourth matrices filled by integer numbers in a certain range should be adjusted. Herein, continuous numbers with uniform distribution in $[0,1]$ are generated, and its related integer is replaced based on which interval each number belongs.

\subsection{Test problem generation}

Since a new network design for a sustainable CLSC is proposed in this study, there is no benchmark or data set in the literature to use for model verification. Therefore, some medium- and large-sized test problems are generated and inspired by the studied case study. Table 7 is used to set the size of the test problems. The test problem parameters are available at http://dx.doi.org/10.17632/3d286djjfd.1.

\section{Computational results and sensitivity analysis}

To demonstrate the effectiveness of the developed hybrid multi-objective algorithm, it is compared with the conventional algorithm (i.e., NSGA-II) based on multiobjective comparison metrics. Firstly, the parameters of the two proposed algorithms are tuned. Then, outputs of the proposed algorithms are reported and compared using bar charts and $t$-test. Finally, the
Table 7. Size of test problems.

\begin{tabular}{cc}
\hline No. & Problem size \\
& $|\boldsymbol{D}| \times|\boldsymbol{G}| \times|\boldsymbol{I}| \times|\boldsymbol{R}| \times|\boldsymbol{S}| \times|\boldsymbol{L}| \times|\boldsymbol{T}|$ \\
\hline 0 & $2 \times 2 \times 5 \times 2 \times 2 \times 10 \times 3$ \\
1 & $3 \times 2 \times 6 \times 2 \times 2 \times 20 \times 3$ \\
2 & $3 \times 2 \times 8 \times 3 \times 2 \times 25 \times 3$ \\
3 & $4 \times 2 \times 12 \times 3 \times 2 \times 30 \times 3$ \\
4 & $6 \times 2 \times 18 \times 4 \times 2 \times 40 \times 4$ \\
5 & $8 \times 3 \times 24 \times 4 \times 3 \times 60 \times 4$ \\
6 & $10 \times 3 \times 30 \times 5 \times 3 \times 80 \times 4$ \\
7 & $12 \times 3 \times 40 \times 8 \times 3 \times 100 \times 5$ \\
8 & $15 \times 3 \times 50 \times 10 \times 3 \times 140 \times 5$ \\
9 & $18 \times 4 \times 60 \times 12 \times 4 \times 180 \times 5$ \\
10 & $20 \times 4 \times 70 \times 15 \times 4 \times 200 \times 6$ \\
\hline
\end{tabular}

sensitivity analysis is done on the selling price of recycled products as an influential parameter.

\subsection{Comparison metrics}

To evaluate the performance of the meta-heuristics, four comparison metrics are applied:

1. Number of Pareto front Solutions (NPS): It refers to the number of non-dominated points that each algorithm obtains, which shows the high ability of each algorithm to find efficient points.

2. Computational Time (CT): It indicates the time taken by each algorithm to find the Pareto front. The low value of $\mathrm{CT}$ shows the better performance of an algorithm.

3. Spacing Metric (SM): It means how non-dominated solutions are distributed throughout the obtained Pareto front. The lower value of the SM shows the more uniform distribution of Pareto points. It is calculated as follows [18]:

$$
\begin{aligned}
& S M=\sqrt{\frac{1}{N P S-1} \sum_{i=1}^{n}\left(d_{i}-\bar{d}\right)^{2}}, \\
& d_{i}=\min _{i \neq j}^{j} \sum_{k=1}^{k}\left|f_{k}^{i}(\vec{x})-f_{k}^{j}(\vec{x})\right| \\
& i, j=1,2, \ldots, N P S,
\end{aligned}
$$

where $\bar{d}$ is the average value of $d_{i}$ s. $\vec{x}$ is the solution vector, $k$ is the index of the $k$ th objective function, and $i$ and $j$ are the indexes of Pareto solutions.

4. Diversity Metric (DM): It distinguishes the spread of solution sets calculated as follows:

$$
D M=\sqrt{\sum_{k=1}^{K}\left(\max _{i} f_{k}-\min _{i} f_{k}\right)^{2}},
$$

where $k$ is the index of the $k$ th objective function, and $i$ is the index of Pareto solutions. 


\subsection{Parameters tuning}

The performance of meta-heuristics is highly dependent on their parameter values; therefore, the calibration of their parameters is essential. Here, the Taguchi Design of Experiment (DOE) method, as a powerful tool for parameter tuning [49], is employed for parameter setting of algorithms. One of the distinctive features of the Taguchi method is achieving the most extensive information by generating the least number of experiments [49].

A three-level Taguchi design is applied to analyze the influence of vital parameters of NSGA-II involving population size $(N p)$, the total number of iterations (Max Iteration), crossover rate $(P c)$, and mutation rate $(\mathrm{Pm})$ shown in Table 8.

Besides the aforementioned parameters, the three levels of repository size $(N r)$, leader selection pressure (Beta), deletion pressure (Gamma), inertia weight $(w)$, personal learning coefficient $\left(c_{1}\right)$, and global learning coefficient $\left(c_{2}\right)$ are given in Table 9 for the proposed NSGA-II-MOPSO algorithm.

Based on the Taguchi method, it is enough to use L9 orthogonal array (nine experiments) for the

Table 8. Levels of parameters for the NSGA-II.

\begin{tabular}{cccc}
\hline NSGA-II & \multicolumn{3}{c}{ Levels } \\
\cline { 2 - 4 } parameters & $\mathbf{1}$ & $\mathbf{2}$ & $\mathbf{3}$ \\
\hline Max iteration & 80 & $100 \checkmark$ & 120 \\
Population size & 50 & 100 & $150 \checkmark$ \\
Crossover probability & 0.6 & $0.7 \checkmark$ & 0.8 \\
Mutation probability & 0.2 & $0.3 \checkmark$ & 0.4 \\
\hline
\end{tabular}

NSGA-II [50] instead of 34 full factorial experiments and L27 orthogonal array (27 experiments) instead of 310 full factorial experiments for the hybrid NSGA-IIMOPSO algorithm. The L9 and L27 orthogonal arrays are available in MINITAB software, version 17.

Here, Taguchi is employed on Problem No. 1. The response variable of the Taguchi is the weighted average of the four main comparison metrics (i.e., CT, NPS, DM, and SM). To avoid the effect of scales on computations, values of metrics should be normalized as follows. If higher values of a metric $(x)$ are desirable (e.g., NPS and DM), it is denoted by $x^{+}$and normalized by Eq. (58). However, if lower values of a metric are desired (e.g., CT and SM), $x^{-}$is its symbol and will be normalized by Eq. (59):

$$
\begin{aligned}
x^{+} \rightarrow r_{i} & =\frac{x_{i}-\min _{i}\left(x_{i}\right)}{\max _{i}\left(x_{i}\right)-\min _{i}\left(x_{i}\right)}, \\
x^{-} \rightarrow r_{i} & =\frac{\max _{i}\left(x_{i}\right)-x_{i}}{\max _{i}\left(x_{i}\right)-\min _{i}\left(x_{i}\right)} .
\end{aligned}
$$

Regarding the NSGA-II, by doing nine experiments with different levels of the parameter, the values of metrics are measured and normalized in Table 10, which also reported weights. Due to the widespread metrics data for the hybrid NSGA-II-MOPSO, their values are not reported here.

Figure 10 shows the experimental results of NSGA-II and NSGA-II-MOPSO parameters tuning. In Taguchi, a robustness measure, signal-to-noise $(\mathrm{S} / \mathrm{N})$ ratio, is used to identify control factors and reduce the effects of noise factors. Higher values of the $\mathrm{S} / \mathrm{N}$ ratio specify control factor settings that minimize the effects of the noise factors [51]. The desirable levels of each

Table 9. Levels of parameters for the hybrid NSGA-II-MOPSO.

\begin{tabular}{cccc}
\hline NSGA-II-MOPSO & \multicolumn{3}{c}{ Levels } \\
\cline { 2 - 4 } parameters & $\mathbf{1}$ & $\mathbf{2}$ & $\mathbf{3}$ \\
\hline Max iteration & $80 \checkmark$ & 100 & 120 \\
Population size & 50 & $100 \checkmark$ & 150 \\
Repository size & $20 \checkmark$ & 40 & 60 \\
Crossover probability & 0.6 & $0.7 \checkmark$ & 0.8 \\
Mutation probability & 0.2 & $0.3 \checkmark$ & 0.4 \\
Beta (leader selection pressure) & 0.8 & $1.2 \checkmark$ & 2.4 \\
Gamma (deletion selection pressure) & 0.8 & 1.2 & $1.4 \checkmark$ \\
Weight of inertia & $0.5 \checkmark$ & 0.7 & 0.9 \\
Personal learning $\left(c_{1}\right)$ & 1 & 1.25 & $1.5 \checkmark$ \\
Global learning $\left(c_{2}\right)$ & $1 \checkmark$ & 1.5 & 2 \\
\hline
\end{tabular}


Table 10. Values and normalized values of metrics for nine NSGA-II experiments.

\begin{tabular}{cccccc}
\hline RUN & $\mathbf{C T}(\mathbf{0 . 2})$ & $\mathbf{N P S ( 0 . 2 )}$ & $\mathbf{D M}(\mathbf{0 . 3})$ & $\mathbf{S M}(\mathbf{0 . 3})$ & Response \\
\hline 1 & 105.142 & 50 & 21421.1 & 613.71 & \\
& $(1)$ & $(0)$ & $(0)$ & $(0.326282)$ & 0.297885 \\
2 & 167.587 & 100 & 85098 & 377.702 & \\
& $(0.867305)$ & $(0.5)$ & $(1)$ & $(0.658177)$ & 0.770914 \\
3 & 371.973 & 150 & 47398.1 & 431.552 & \\
& $(0.432989)$ & $(1)$ & $(0.40795)$ & $(0.58245)$ & 0.583718 \\
4 & 173.621 & 50 & 76568.1 & 439.558 & \\
& $(0.854483)$ & $(0)$ & $(0.866045)$ & $(0.57119)$ & 0.602067 \\
5 & 441.866 & 97 & 44443.6 & 396.191 & \\
& $(0.284467)$ & $(0.47)$ & $(0.361552)$ & $(0.632177)$ & 0.449012 \\
6 & 410.854 & 147 & 76998.4 & 134.635 & \\
& $(0.350367)$ & $(0.97)$ & $(0.872801)$ & $(1)$ & 0.825914 \\
7 & 152.874 & 50 & 48602.8 & 327.439 & \\
& $(0.898570)$ & $(0)$ & $(0.426869)$ & $(0.728862)$ & 0.526433 \\
8 & 449.621 & 100 & 46711.6 & 669.836 & \\
& $(0.267988)$ & $(0.5)$ & $(0.397169)$ & $(0.247354)$ & 0.346954 \\
& 575.734 & 150 & 59786.4 & 845.727 & \\
& $(0)$ & $(1)$ & $(0.602499)$ & $(0)$ & 0.38075 \\
\hline \multirow{2}{*}{5} & & & & &
\end{tabular}

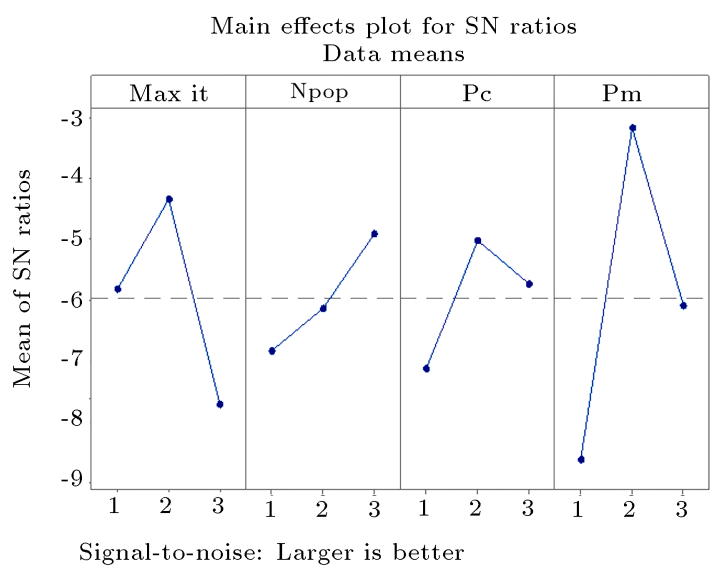

(a)

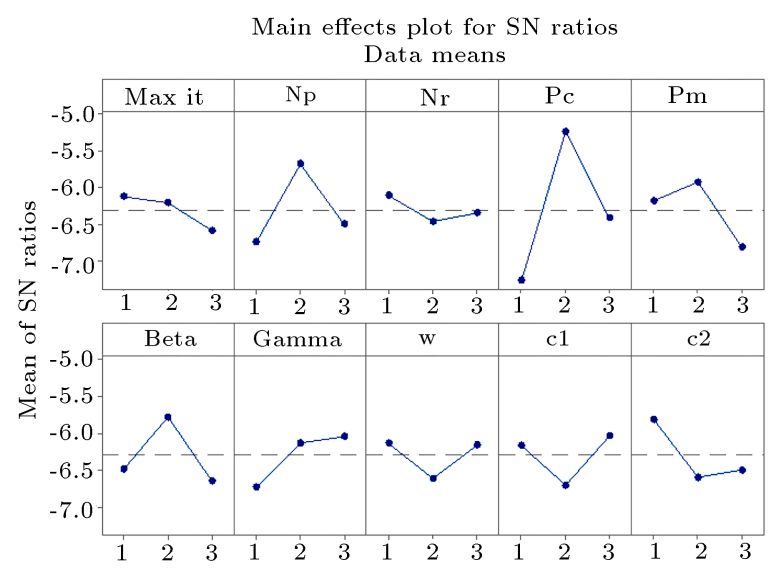

Signal-to-noise: Larger is better

(b)

Figure 10. NSGA-II (a) and NSGA-II-MOPSO (b) parameters tuning by the Taguchi DOE.

parameter, which have the maximum mean of the $\mathrm{S} / \mathrm{N}$ ratio, are marked in Tables 8 and 9.

\subsection{Results of meta-heuristics}

In this section, the case study described in Section 4.1 is solved by two developed meta-heuristics, and obtained results are compared with those obtained by the $\mathrm{TH}$ method. For this purpose, both meta-heuristics are coded in MATLAB version R2016b. The value of each objective function reported in Table 11 is the average of that objective function values for obtained Pareto solutions. As shown in Table 11, the solving time of two developed meta-heuristics is much shorter than the $\mathrm{TH}$ method. The results reported in this table verify the acceptable performance of developed algorithms in both speed and accuracy for small-sized problems. The medium- and large-sized problems generated in Section 4.6 are not solvable by the $\mathrm{TH}$ method in a reasonable time. Therefore, these problems are solved using only two developed meta-heuristics, and 
Table 11. Results of solving the case study by the developed meta-heuristic algorithm.

\begin{tabular}{ccccc}
\hline Problem (0) & \multicolumn{4}{c}{$\mathbf{2} \times \mathbf{2} \times \mathbf{5} \times \mathbf{2} \times \mathbf{2} \times \mathbf{7} \times \mathbf{3}$} \\
\hline Solving method & $\mathbf{o b j ~ \mathbf { 1 }}$ & $\mathbf{o b j ~} \mathbf{2}$ & $\mathbf{o b j ~} \mathbf{3}$ & $\begin{array}{c}\text { Computational } \\
\text { time } \\
(\mathbf{s})\end{array}$ \\
\hline Exact & 10037.02 & 6123.415 & 57.9726 & 1440 \\
NSGA-II & 10945 & 6490 & 54.9 & 210.922 \\
NSGA-II-MOPSO & 10578 & 6753 & 52.6 & 160.56 \\
\hline
\end{tabular}

Table 12. Objective function values of medium- and large-sized problems.

\begin{tabular}{cccccccc}
\hline & \multicolumn{5}{c}{ Solving } & \multicolumn{3}{c}{$\begin{array}{c}\text { method } \\
\text { NSGA-II }\end{array}$} & & \multicolumn{2}{c}{ NSGA-II-MOPSO } \\
\cline { 2 - 4 } \cline { 7 - 8 } Number & Obj 1 & Obj 2 & Obj 3 & & Obj 1 & Obj 2 & Obj 3 \\
\hline 1 & 23482 & 9565.29 & 19 & & 34413 & 9518.5 & 19 \\
2 & 43904.5 & 18237.5 & 20.5 & & 24034 & 20930 & 20 \\
3 & 53861.5 & 28073.5 & 22.5 & & 44598.5 & 28509 & 28 \\
4 & 67791 & 50094.5 & 56.5 & & 100870 & 64892.5 & 57.5 \\
5 & 96077 & 75479 & 84 & & 149520 & 77120 & 80 \\
6 & 163575 & 90897 & 105 & & 176315 & 90390 & 105 \\
7 & 262445 & 153760 & 165 & & 307975 & 16941.5 & 185 \\
8 & 293430 & 179815 & 200 & & 418805 & 206910 & 220 \\
9 & 371120 & 212640 & 240 & & 538555 & 255265 & 290 \\
10 & 584590 & 312140 & 370 & & 665140 & 345065 & 405 \\
\hline Avg. & 196028 & 113070 & 128.25 & & 246023 & 111554 & 140.95 \\
\hline
\end{tabular}

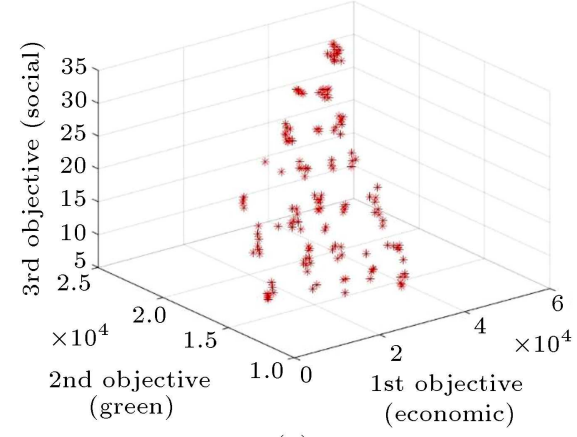

(a)

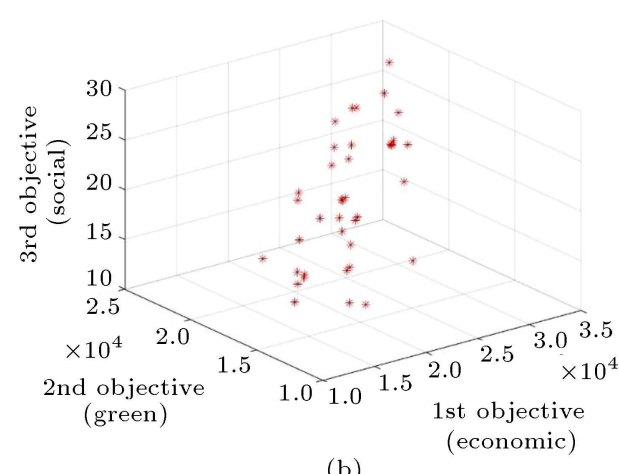

(b)

Figure 11. NSGA-II (a) and NSGA-II-MOPSO (b) Pareto front for Problem No. 1.

the average of objective functions regarding the Pareto front is reported in Table 12 .

The Pareto solutions for Problem No. 1 obtained by the NSGA-II and NSGA-II-MOPSO algorithms are depicted in Figure 11. Table 13 reports the value of comparison metrics for both algorithms. The values of metrics show the acceptable performance of the developed algorithms. As shown, by increasing the problem size, the CT is also increased, but not in a nonpolynomial manner. According to Figure 12, although the NSGA-II generates more Pareto solutions than the
NSGA-II-MOPSO, the NSGA-II-MOPSO algorithm has shorter CT due to the application of global and personal best memory. Compared with the hybrid algorithm, the average of the CT for the NSGA-II is about 2.5 times higher.

The comparison of the NPS and the CT is visible by visual tools. However, a statistical paired t-test is applied to compare the two algorithms based on DM and SM [52]. Is there any difference in the mean of metrics? The paired $t$-test checks the hypothesis that DM and SM averages of the problem solved by the 
Table 13. Comparison of metrics for all test problems solved by the meta-heuristic algorithms.

\begin{tabular}{|c|c|c|c|c|c|c|c|c|}
\hline \multirow[b]{3}{*}{ Number } & \multicolumn{8}{|c|}{ Solving method } \\
\hline & \multicolumn{4}{|c|}{ NSGA-II } & \multicolumn{4}{|c|}{ NSGA-II+MOPSO } \\
\hline & NPS & CT & SM & DM & NPS & $\mathrm{CT}$ & SM & DM \\
\hline 1 & 149.5 & 686.01 & 587.86 & 50283.46 & 43 & 280.94 & 1275.11 & 39215.91 \\
\hline 2 & 150 & 564.84 & 450.66 & 66974.38 & 27 & 175.39 & 1831.28 & 31659.29 \\
\hline 3 & 150 & 740.79 & 1097.46 & 84805.57 & 36 & 329.55 & 2549.86 & 63160.06 \\
\hline 4 & 150 & 1289.04 & 1063.99 & 82289.67 & 30.5 & 516.20 & 2259.80 & 63363.62 \\
\hline 5 & 150 & 1829.46 & 1589.44 & 115534.84 & 24 & 719.83 & 3031.04 & 67915.54 \\
\hline 6 & 150 & 2413.91 & 2173.89 & 196498.64 & 32 & 919.88 & 3200.55 & 101544.32 \\
\hline 7 & 148 & 3548.40 & 3766.65 & 270177.99 & 21.5 & 1361.19 & 4559.14 & 104738.16 \\
\hline 8 & 150 & 5357.59 & 4252.88 & 315787.54 & 24.5 & 2111.51 & 5047.74 & 176943.67 \\
\hline 9 & 150 & 7149.93 & 3660.71 & 380093.08 & 17.5 & 2476.42 & 6054.67 & 143434.65 \\
\hline 10 & 150 & 9415.76 & 4403.10 & 438262.53 & 22 & 4526.44 & 6585.65 & 122197.37 \\
\hline Avg. & 149.75 & 3299.57 & 2304.66 & 200070.77 & 27.8 & 1341.74 & 3639.48 & 91417.26 \\
\hline
\end{tabular}

Table 14. Results of the paired $t$-test for the DM and the SM.

\begin{tabular}{|c|c|c|c|c|c|c|c|c|c|c|}
\hline \multirow[b]{2}{*}{ Metrics } & \multicolumn{2}{|c|}{ Mean } & \multicolumn{2}{|c|}{ STD } & \multirow[b]{2}{*}{ 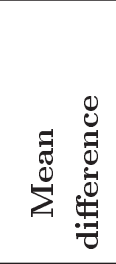 } & \multicolumn{2}{|c|}{$\begin{array}{c}\text { Confidence } \\
\text { interval }\end{array}$} & \multirow[b]{2}{*}{$t$-value } & \multirow[b]{2}{*}{$D F$} & \multirow[b]{2}{*}{$p$-value } \\
\hline & 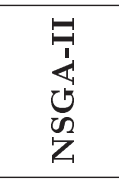 & 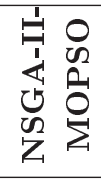 & 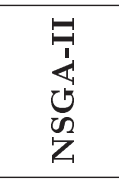 & 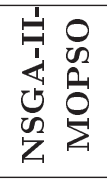 & & down & up & & & \\
\hline $\mathrm{DM}$ & 200071 & 91417 & 134877 & 44364 & 108654 & 42156 & 175151 & 3.64 & 9 & 0.005 \\
\hline $\mathrm{SM}$ & 2305 & 3639 & 1486 & 1728 & -1330 & -1702 & -968 & -8.10 & 9 & 0 \\
\hline
\end{tabular}

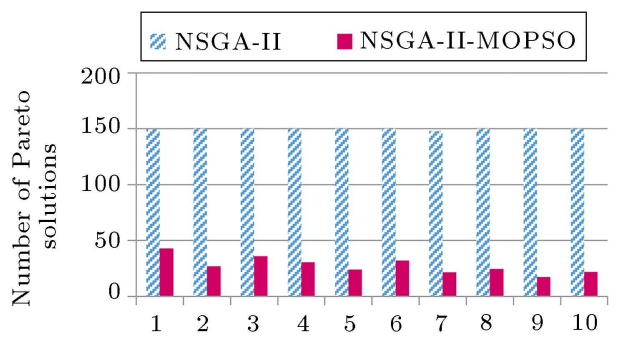

(a)

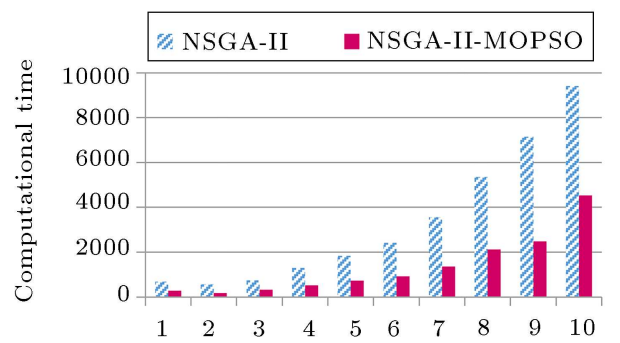

(b)

Figure 12. NPS (a) and CT (b) of the NSGA-II versus the NSGA-II-MOPSO.

hybrid algorithm remain equal to the DM and the SM averages of the problem solved by NSGA-II. Since DM and SM have a normal distribution, the paired $t$-test is allowed to be used. At a confidence level of $95 \%$, if the $p$-value is under 0.05 , the hypothesis is rejected. The outputs of running the paired $t$-test are reported in Table 14 to determine the best algorithm.

Regarding Table 14, the $p$-value is less than 0.05 for both the DM and SM metrics. Therefore, there is a meaningful difference in the performance of two algorithms. Based on the obtained statistical data, the NSGA-II has higher diversity with less spacing than the NSGA-II-MOPSO and, consequently, has better performance in terms of the DM and SM metrics. However, if the decision-maker cares about the CT, a hybrid algorithm should be selected.

\subsection{Sensitivity analysis}

Since the selling price of recycled products to the secondary market, $P_{t}$, is a significant parameter in the considered problem, this parameter is analyzed here. It is a prominent parameter, because if this price is deducted, perhaps the retailer will not be able to bear the holding cost of perishable inventory plus the risk of not selling it. The results of the sensitivity analysis on Pt are shown in Figure 13. According to Figure 13(a), 


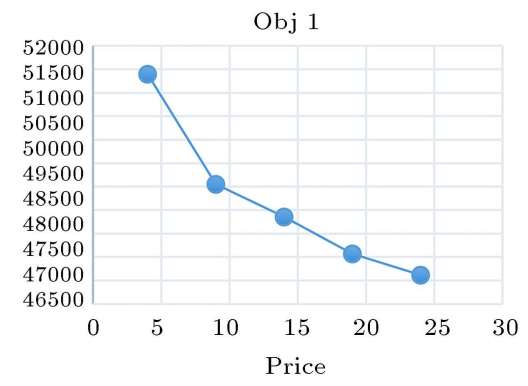

(a)

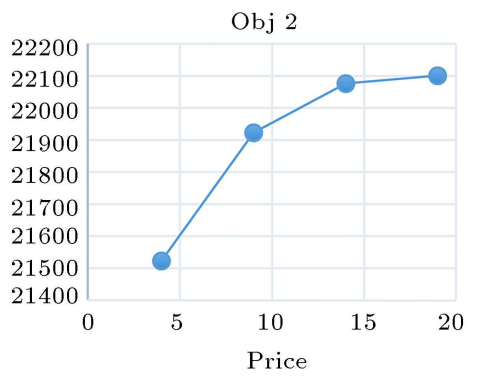

(b)

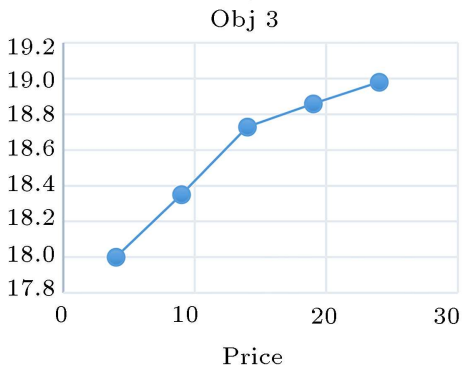

(c)

Figure 13. Economic (a), environmental (b), social (c), and effects of the selling price of recycled products.

since increasing the price of selling recycled products to the secondary market up to six times brings about greater profit, the first objective function experiences a decreasing trend $(-8.33 \%)$, while it causes more RCs to operate, which in turn increases the employment rate. Herein, an increase in the social objective function is observed $(+5.44 \%)$ in Figure 13(c). When the retailers know that the expired products can be sold out to the secondary market at higher prices, more products will be delivered to the retailers, resulting in increased vehicle FCR and GHG emissions $(+2.85 \%)$ (Figure 13(b)). Consequently, it is imperative to decide on this price at first and, then, plan the supply chain network.

\section{Conclusions and future research}

This study proposed a new sustainable locationrouting-inventory model, called Closed-Loop LocationRouting- Inventory Problem (CL-LRIP), to plan an efficient closed-loop supply chain for perishable products. To do this, a multi-objective mathematical programming model was proposed to minimize the total costs and environmental impacts while maximizing the utility of three main network stakeholders. Then, the chance-constrained possibilistic programming method was employed to encounter uncertainty in the parameters of the model. Afterward, the TH method was applied to convert the multi-objective model into a single one solved by CPLEX solver of GAMS software. Since the problem is NP-complete, exact methods were inefficient to solve the problem in large-sized instances. Hence, a hybrid metaheuristic algorithm was developed to solve the proposed model in largesized instances. The obtained results showed the efficiency and performance of the proposed model and the applied NSGA-II-MOPSO algorithm. Likewise, the results pointed to the validity and applicability of the proposed model in a case study from the bread industry. The results of solving the problem indicated that the developed hybrid algorithm can obtain highquality solutions with $89 \%$ lower CPU time than the exact method. Finally, a sensitivity analysis was conducted on important parameters of the proposed model and the obtained results demonstrated that the sale price of the recycled products had a significant impact on sustainability goals, such that increasing it by six times caused an $8.33 \%$ decrease in the economic objective, a $2.83 \%$ rise in environmental side-effects, and a $5.44 \%$ increase in social goals. Therefore, supply chain managers are required to determine the prices at the secondary market before the planning of the supply chain. Some of the future research directions are:

i) Considering the risk of roads' or facilities' disruption;

ii) Tacking into account scheduling decisions of the plant;

iii) Embedding pricing decisions of the second bazaar into the developed model. Moreover, solving the problem with a customized exact method or finding a lower bound for it can be a contribution to the solution methods.

\section{Acknowledgments}

The authors would like to thank the editor and anonymous reviewers for their helpful comments, which greatly improved the quality of this research work.

\section{References}

1. Gustavsson, J. and Cederberg, C., Global Food Losses and Food Waste, Food and Agriculture Organization of the United Nations, Rome (2011).

2. Govindan, K., Jafarian, A., Khodaverdi, R., and Devika, K. "Two-echelon multiple-vehicle location routing problem with time windows for optimization of sustainable supply chain network of perishable food", Intern J. Prod. Econ., 152, pp. 9-28 (2014). https://doi.org/10.1016/j.ijpe.2013.12.028

3. Parfitt, J., Barthel, M., and Macnaughton, S. "Food waste within food supply chains: quantification and potential for change to 2050", Philos. Trans. R. Soc. B Biol. Sci., 365(1554), pp. 3065-3081 (2010). https://doi.org/10.1098/rstb.2010.0126 
4. Sazvar, Z., Mirzapour Al-e-hashem, S.M.J., Govindan, K., et al. "A novel mathematical model for a multiperiod, multi-product optimal ordering problem considering expiry dates in a FEFO system", Transp. Res. Part E Logist. Transp. Rev., 93, pp. 232-261 (2016). https://doi.org/10.1016/j.tre.2016.04.011

5. Devika, K., Jafarian, A., and Nourbakhsh, V. "Designing a sustainable closed-loop supply chain network based on triple bottom line approach: A comparison of metaheuristics hybridization techniques", Eur. J. Oper. Res., 235(3), pp. 594-615 (2014). https://doi.org/10.1016/j.ejor.2013.12.032

6. Seuring, S. and Müller, M. "From a literature review to a conceptual framework for sustainable supply chain management", J. Clean. Prod., 16(15), pp. 1699-1710 (2008). https://doi.org/10.1016/j.jclepro.2008.04.020

7. Eskandarpour, M., Dejax, P., Miemczyk, J., et al. "Sustainable supply chain network design: An optimization-oriented review", Omega, 54, pp. 11-32 (2015). https://doi.org/10.1016/j.omega.2015.01.006

8. Govindan, K., Soleimani, H., and Kannan, D. "Reverse logistics and closed-loop supply chain: A comprehensive review to explore the future", Intern J. Prod. Econ., 240(3), pp. 603-626 (2015). https://doi.org/10.1016/j.ejor.2014.07.012

9. Kim, T., Glock, C.H., and Kwon, Y. "A closed-loop supply chain for deteriorating products under stochastic container return times", Omega, 43, pp. 30-40 (2014). https://doi.org/10.1016/j.omega.2013.06.002

10. Moon, I., Salhi, S., and Feng, X. "The locationrouting problem with multi-compartment and multitrip: formulation and heuristic approaches", Transp. A Transp. Sci., 16(3), pp. 501-528 (2020). https://doi.org/10.1080/23249935.2020.1720036

11. Zhalechian, M., Tavakkoli-Moghaddam, R., Zahiri, B., et al. "Sustainable design of a closed-loop locationrouting-inventory supply chain network under mixed uncertainty", Transp. Res. Part E Logist. Transp. Rev., 89, pp. 182-214 (2016).

https://doi.org/10.1016/j.tre.2016.02.011

12. European Commission, Circular Economy - Clear Targets and Tools for Better Waste Management, European Commission (2015).

13. Ramezani, M., Bashiri, M., and TavakkoliMoghaddam, R. "A new multi-objective stochastic model for a forward/reverse logistic network design with responsiveness and quality level", Appl. Math. Model., 37(1-2), pp. 328-344 (2013). https://doi.org/10.1016/j.apm.2012.02.032

14. Banasik, A., Kanellopolos, A., and Claassen, G.D.H. "closing loops in agricultural supply chains using multi objective optimization: A case study of an industrial mushroom supply chain", Int. J. Prod. Econ., 183, pp. 409-420 (2017).

15. Pishvaee, M.S., Rabbani, M., and Torabi, S.A. "A robust optimization approach to closed-loop supply chain network design under uncertainty", Appl. Math.
Model., 35(2), pp. 637-649 (2011).

https://doi.org/10.1016/j.apm.2010.07.013

16. Rahimi, M., Baboli, A., and Rekik, Y. "Sustainable inventory routing problem for perishable products by considering reverse logistic", IFAC-Pap., 49(12), pp. 949-954 (2016). https://doi.org/10.1016/j.ifacol.2016.07.898

17. Khalili-Damghani, K., Abtahi, A.-R., and Ghasemi, A. "A new bi-objective location-routing problem for distribution of perishable products: Evolutionary computation approach", J. Math. Model. Algorithms Oper. Res., 14(3), pp. 287-312 (2015). https://doi.org/10.1007/s10852-015-9274-3

18. Rabbani, M., Navazi, F., Farrokhi-Asl, H., et al. "A sustainable transportation-location-routing problem with soft time windows for distribution systems", Uncertain Supply Chain Manag., 6(3), pp. 229-254 (2018). https://doi.org/10.5267/j.uscm.2017.12.002

19. Sazvar, Z., Rahmani, M., and Govindan, K. "A sustainable supply chain for organic, conventional agro-food products: The role of demand substitution, climate change and public health", J. Clean. Prod., 194, pp. 564-583 (2018).

https://doi.org/10.1016/j.jclepro.2018.04.118

20. Sazvar, Z. and Sepehri, M. "An integrated replenishment-recruitment policy in a sustainable retailing system for deteriorating products", Socioecon. Plann., Sci., 69(February 2019), 100686 (2020). https://doi.org/10.1016/j.seps.2019.02.001

21. Bakker, M., Riezebos, J., and Teunter, R.H. "Review of inventory systems with deterioration since 2001", Eur. J. Oper. Res., 221(2), pp. 275-284 (2012). https://doi.org/10.1016/j.ejor.2012.03.004

22. Sepehri, M. and Sazvar, Z. "Multi-objective sustainable supply chain with deteriorating products and transportation options under uncertain demand and backorder", Scientia Iranica, 23(6), pp. 2977-2994 (2016). https://doi.org/10.24200/sci.2016.4006

23. Caracciolo, F., Amani, P., Cavallo, C., et al. "The environmental benefits of changing logistics structures for fresh vegetables", Int. J. Sustain. Transp., 12(4), pp. 233-40 (2018). https://doi.org/10.1080/15568318.2017.1337834

24. Chaudhary, V., Kulshrestha, R., and Routroy, S. "State-of-the-art literature review on inventory models for perishable products", J. Adv. Manag. Res., 15(3), pp. 306-346 (2018). https://doi.org/10.1108/JAMR-09-2017-0091

25. Teng, J-T., Cárdenas-Barrón, L.E., Chang, H-J., et al. "Inventory lot-size policies for deteriorating items with expiration dates and advance payments", Appl. Math. Model., 40(19-20), pp. 8605-8616 (2016). https://doi.org/10.1016/j.apm.2016.05.022

26. Ketzenberg, M., Gaukler, G., and Salin, V. "Expiration dates and order quantities for perishables", Eur. J. Oper. Res., 266(2), pp. 569-584 (2018). https://doi.org/10.1016/j.ejor.2017.10.005 
27. Singh, S., Khurana, D., and Tayal, S. "An economic order quantity model for deteriorating products having stock dependent demand with trade credit period and preservation technology", Uncertain Supply Chain Manag., 4(1), pp. 29-42 (2016).

28. Weiss, H.J. "Economic order quantity models with nonlinear holding costs", Eur. J. Oper. Res., 9(1), pp. 56-60 (1982).

https://doi.org/10.1016/0377-2217(82)90010-8

29. San-José, L.A., Sicilia, J., Cárdenas-Barrón, L.E., et al. "Optimal price and quantity under power demand pattern and non-linear holding cost", Comput. Ind. Eng., 129, pp. 426-434 (2019).

https://doi.org/10.1016/j.cie.2019.01.054

30. Sazvar, Z., Mirzapour Al-E-Hashem, S.M.J., Baboli, A., et al. "A bi-objective stochastic programming model for a centralized green supply chain with deteriorating products", Int. J. Prod. Econ., 150, pp. 140-154 (2014).

https://doi.org/10.1016/j.ijpe.2013.12.023

31. Rahimi, M., Baboli, A., and Rekik, Y. "Multiobjective inventory routing problem: A stochastic model to consider profit, service level and green criteria", Transp. Res. Part E Logist. Transp. Rev., 101, pp. 59-83 (2017).

https://doi.org/10.1016/j.tre.2017.03.001

32. Ahmadi Javid, A. and Azad, N. "Incorporating location, routing and inventory decisions in supply chain network design", Transp. Res. Part E Logist. Transp. Rev., 46(5), pp. 582-597 (2010). https://doi.org/10.1016/j.tre.2009.06.005

33. Prodhon, C. and Prins, C. "A survey of recent research on location-routing problems", Eur. J. Oper. Res., 238(1), pp. 1-17 (2014).

https://doi.org/10.1016/j.ejor.2014.01.005

34. Nekooghadirli, N., Tavakkoli-moghaddam, R., Ghezavati, V.R., et al. "Solving a new bi-objective locationrouting-inventory problem in a distribution network by meta-heuristics", Comput. Ind. Eng., 76(1), pp. 204221 (2014)

https://doi.org/10.1016/j.cie.2014.08.004

35. Ghorbani, A. and Akbari Jokar, M.R. "A hybrid imperialist competitive-simulated annealing algorithm for a multisource multi-product location-routing-inventory problem", Comput. Ind. Eng., 101, pp. 116-127 (2016). https://doi.org/10.1016/j.cie.2016.08.027

36. Tavakkoli-Moghaddam, R. and Raziei, Z. "A new bi-objective location-routing-inventory problem with fuzzy demands", IFAC-Pap., 49(12), pp. 1116-1121 (2016). https://doi.org/10.1016/j.ifacol.2016.07.646

37. Zheng, X., Yin, M., and Zhang, Y. "Integrated optimization of location, inventory and routing in supply chain network design", Transp. Res. Part B Methodol., 121, pp. 1-20 (2019). https://doi.org/10.1016/j.trb.2019.01.003
38. Karakostas, P., Sifaleras, A., and Georgiadis, M.C. "A general variable neighborhood search-based solution approach for the location-inventory-routing problem with distribution outsourcing", Comput. Chem. Eng., 126, pp. 263-279 (2019). https://doi.org/10.1016/j.compchemeng.2019.04.015

39. Hiassat, A., Diabat, A., and Rahwan, I. "A genetic algorithm approach for location-inventory-routing problem with perishable products", J. Manuf. Syst., 42, pp. 93-103 (2017). https://doi.org/10.1016/j.jmsy.2016.10.004

40. Rafie-Majd, Z., Pasandideh, S.H.R., and Naderi, B. "Modelling and solving the integrated inventorylocation-routing problem in a multi-period and multiperishable product supply chain with uncertainty: Lagrangian relaxation algorithm", Comput. Chem. Eng., 109, pp. 9-22 (2018). https://doi.org/10.1016/j.compchemeng.2017.10.013

41. Navazi, F., Tavakkoli-Moghaddam, R., Sazvar, Z., et al. "Sustainable design for a bi-level transportationlocation-vehicle routing scheduling problem in a perishable product supply chain", in: Borangiu T, Trentesaux D, Thomas A, Cavalieri S (Eds.), Service Orientation in Holonic and Multi-Agent Manufacturing, Springer International Publishing, Cham, pp. 308-321 (2018).

42. Soysal, M. "Closed-loop inventory routing problem for returnable transport items", Transp. Res. Part Transp. Environ., 48, pp. 31-45 (2016). https://doi.org/10.1016/j.trd.2016.07.001

43. Xiao, Y., Zhao, Q., Kaku, I., et al. "Development of a fuel consumption optimization model for the capacitated vehicle routing problem", Comput. Oper. Res., 39(7), pp. 1419-1431 (2012). https://doi.org/10.1016/j.cor.2011.08.013

44. Mirzapour Al-e-hashem, S.M.J., Baboli, A., and Sazvar, Z. "A stochastic aggregate production planning model in a green supply chain: Considering flexible lead times, nonlinear purchase and shortage cost functions", Eur. J. Oper. Res., 230(1), pp. 26-41 (2013). https://doi.org/10.1016/j.ejor.2013.03.033

45. Pishvaee, M.S., Razmi, J., and Torabi, S.A. "Robust possibilistic programming for socially responsible supply chain network design: A new approach", Fuzzy Sets Syst., 206, pp. 1-20 (2012). https://doi.org/10.1016/j.fss.2012.04.010

46. Torabi, S.A. and Hassini, E. "An interactive possibilistic programming approach for multiple objective supply chain master planning", Fuzzy Sets Syst., 159, pp. 193-214 (2008). https://doi.org/10.1016/j.fss.2007.08.010

47. Deb, K., Pratap, A., Agarwal, S., et al. "A fast and elitist multiobjective genetic algorithm", IEEE Trans. Evol. Comput., 6(2), pp. 182-197 (2002).

48. Reyes-sierra, M. and Coello, C.A.C. "Multi-objective particle swarm optimizers: A survey of the state-ofthe-art", Int. J. Comput. Intell. Res., 2(3), pp. 287308 (2006). 
49. Rabbani, M., Navazi, F., Eskandari, N., et al. "A green transportation location-inventory-routing problem by dynamic regional pricing", J. Ind. Eng. Manag. Stud., 7(1), pp. 35-58 (2020).

50. Forouzanfar, F., Tavakkoli-Moghaddam, R., Bashiri, M., et al. "New mathematical modeling for a locationrouting-inventory problem in a multi-period closedloop supply chain in a car industry", J. Ind. Eng. Int., 14(3), pp. 537-553 (2018).

51. Arab, R., Ghaderi, S.F., and Tavakkoli-Moghaddam, R. "Bi-objective inventory routing problem with backhauls under transportation risks: two metaheuristics", Transp. Lett., 12(2), pp. 113-129 (2020). https://doi.org/ 19427867.2018.1533624

52. Vahdani, B., Shekari, D.V.N., and Mousavi, S.M. "Multi-objective, multi-period location-routing model to distribute relief after earthquake by considering emergency roadway repair", Neural Comput. Appl., 30(3), pp. 835-854 (2016).

https://doi.org/10.1007/s00521-016-2696-7

\section{Biographies}

Fatemeh Navazi is an Industrial Engineer. She obtained her BSc and MSc degrees in Industrial Engineering from Alzahra University (2016) and University of Tehran (2018), respectively. Her current research interests include operations research, supply chain management, sustainability, health care, and data science. She is interested in fuzzy, possibilistic, and robust solving methods, besides hybrid meta-heuristic algorithms.
Zeinab Sazvar received her BSc, MSc, and $\mathrm{PhD}$ degrees in Industrial Engineering from Sharif University of Technology (SUT) in 2008, 2010, and 2014, respectively. She also received her second $\mathrm{PhD}$ in Production Management from INSA de Lyon University. She is currently working as an Assistant Professor at University of Tehran (UT). Her research interests include operations and service management, sustainable supply chain management, and mathematical programming.

Reza Tavakkoli-Moghaddam is a Professor of Industrial Engineering at College of Engineering, University of Tehran in Iran. He obtained his BSc, MSc, and PhD from Iran University of Science and Technology in Tehran (1989), University of Melbourne in Melbourne (1994), and Swinburne University of Technology in Melbourne (1998), respectively. He serves as the Editor-in-Chief of two journals and the Editorial Board of five journals. He was the recipient of the 2009 and 2011 Distinguished Researcher Awards as well as the 2010 and 2014 Distinguished Applied Research Awards by University of Tehran in Iran. He was also selected as National Iranian Distinguished Researcher in 2008 and 2010 by the Ministry of Science, Research, and Technology (MSRT) in Iran. He obtained an outstanding rank as the top $1 \%$ scientist and researcher in the world elite group, reported by Thomson Reuters in 2014. Professor TavakkoliMoghaddam has published 5 books, 24 book chapters, and more than 1000 papers in reputable academic journals and conferences. 